\title{
Safety Maintains Lean Sustainability and Increases Performance through Fault Control
}

\author{
Samia Elattar $1,2, *$, Ahmed M. Abed ${ }^{3, *(1)}$ and Fadwa Alrowais $4, *$ (1) \\ 1 Department of Industrial and Systems Engineering, College of Engineering, Princess Nourah bint \\ Abdulrahman University, Riyadh 84428, Saudi Arabia \\ 2 Department of Industrial Engineering, Alexandria Higher Institute of Engineering and Technology (AIET), \\ Alexandria 21311, Egypt \\ 3 Department of Industrial Engineering, Zagazig University, Zagazig 44519, Egypt \\ 4 Department of Computer Sciences, College of Computer and Information Sciences, Princess Nourah bint \\ Abdulrahman University, Riyadh 84428, Saudi Arabia \\ * Correspondence: saelattar@pnu.edu.sa (S.E.); Ahmed-abed@zu.edu.eg (A.M.A.); fmalrowais@pnu.edu.sa (F.A.)
}

Received: 16 August 2020; Accepted: 24 September 2020; Published: 29 September 2020

\begin{abstract}
Almost every industrial and service enterprise adopts some form of Environmental Health and Safety (HSE) practices. However, there is no unified measurement implementation framework to resist losses exacerbated due to the "lack of safety precautions", which must be considered one of the most dangerous Lean wastes because it jeopardizes the investment in the Hex-Bottom-Line (HBLs). Despite the widespread nature of the Lean approach, there no unified and collected framework to track and measure the effectiveness of the safety measures' progress. Therefore, the enterprises resort to establishing their own tailored safety framework that maintains their competitiveness and sustainability. The enterprises must provide insight into safety deficiencies (i.e., faults and losses suffered) that have been measured via downtime spans and costs (Lean waste), reflecting the poor Lean Safety Performance Level (LSPL). This paper aims to shed light on two issues: (1) the adverse impact of the "lack of safety precautions" on LSPL caused by the absence of (2) a Lean Safety framework included in the Measurement and Analysis phases of Define Measure Analyze Identify Control (DMAIC). This framework is based on forecasting losses and faults according to their consumption time. The proposed framework appreciates the losses' severity (time consumption and costs) via Fault Mode and Effect Forecasting (FMEF) aided by Artificial Neural Networks through sequential steps known as Safety Function Deployment (SFD).
\end{abstract}

Keywords: safety procedures; Lean management; loss function; Fault Tree Analysis (FTA)

\section{Introduction}

Sustainability in competitiveness is the main objective of industrial engineering philosophies, especially "the Lean", in providing better waste disposal results. The scientific interdisciplinary community resort to drawing attention to the consequences of neglecting to follow safety procedures (i.e., lack of safety precautions), which is considered the most dangerous Lean waste that must be tracked and controlled. The research mimics Pudar's [1] interest in cyber fault activities via modeling its cyber-attacks (faults/wastes) and countermeasures. Pudar's research considered looking at the faults due to the lack of safety leading to working disruption (i.e., downtime spans) due to workers' faults. This work adopts a stochastic tree approach [2] aided by dynamic Petri-net as one of the most intuitive tools in detecting the nature of periodic faults based on their costs and reparability (i.e., Lean Safety Performance Level). Pudar resorted to measuring its model's performance via validated quantitative metrics used to describe a vulnerable/threatened system due to the lack of safety 
procedures. Therefore, the Lean has been nominated for its statistical ability to predict and analyze all potential faults leading to the downtime spans and valuation of its costs through two sequential methods. The first method is based on the test of the process sequence and its workers' execution time, according to the approach of Novak and other researchers [3,4], which use a sequential fault diagnostic tool. The second method focuses on watching the processes and workers continuously executing their work to detect any faults that violate the safety precautions in time.

The OSHA enacted the regulation for Processes Safety Management (PSM) of hazards in 1992, which highlighted management controls by mitigating the risks related to the use of hazardous materials [5]. This was later manipulated by DuPont in 2016 [6]. The OSHA instructions are considered an approved approach aiming to combat faults. Nevertheless, it missed proactive or unified actions to create control steps to hazardous workers' activity faults leading to disastrous consequences. The proposed framework has a pivotal role in the management of workplace-related health and safety, similar to how the Energy Institute [7] recommended. Previous approaches have been based on monitoring processes' symptoms to the standard deviation of its executing time (i.e., causing dangerous deviations). Other researchers tend to use heuristic algorithms to analyze the most effective costs, for example, those by Pattipati and Alexandridis [8] and Price [9], who used a loss function analysis. However, these methods are limited to processes in which only a single fault is expected to exist at a specific time. Rao [10] developed two algorithms for extracting data from directed graphs to diagnose single failures at a specific time. Shakeri et al. [8] focused on developing a series of tests to document and diagnose the causes of multiple malfunctions but encountered a problem in its lengthy diagnosing time. Another manner used by Price et al. [11], Paash and Mocko [12] analyzed multiple faults that appear in Value-Added (VA) or Necessary Non-Value-Added (NNVA) activities but do not affect the process' continuity when they occur. Therefore, they revamped their analysis using Fault Tree Analysis (FTA) to develop a fault matrix manipulation method according to Yue [13]. Failure Modes and Effect Analysis (FMEA) is a well-known form of qualitative analysis of malfunctions that can be used to identify potential failure processing modes and their causes to evaluate their severity level according to Anvari [14], and the effects on functional stability that are associated with the occurrence of these failure modes. The proposed framework was inspired by FMEA by replacing the analysis stage with an effect forecast stage to become Fault Mode and Effect Forecasted (FMEF), paving the way for the establishment of fault elimination scenarios and control processes. Methods proposed by Papadopoulos [2] and Underwood et al. [15] depend on FTA charts to provide continuous monitoring and rectification of the functions' path in time. Many function failures are not due to one single fault but result from multiple related faults as Shakeri states. Therefore, it is important to predict and diagnose them promptly $[16,17]$ after determining their severity and occurrence frequency. Ikuma decided to combine Lean strategies and traditional safety analysis tools (e.g., using Safety and Lean Integrated Kaizen (SLIK)) as recommended by Anvari et al. [14] and Ikuma [18]. This integration is based on analyzing an improving the current processes (as-is) situation, which is driven by DMAIC. In 2015, Ikuma claimed that VA activities increased by $16 \%$ and the framing crew's overall output by $55 \%$.

In this sense, this work proposes a roadmap that includes the same previous frameworks with another optimization tool, Neural Networks (NN). The proposed approach is named the Sustainable Lean Safety Map (LSPL) derived from the DMAIC. It tracks the LSPL value by establishing one Hex-Bottom-Line (HBLs) element's paradigm by generating a conceptual framework to understand Lean Safety HBL profoundly, reducing losses from the wasteful practices (i.e., risk and hazard issues). The unified Lean Safety framework works with LSPL stages, which are diachronic closely with HBL's investments (e.g., society, environment, economy, policy, technology, and enlightenment). The main characteristic of safety is a resistance to any risks threatening the survival situation (to-be) and then mitigating them to achieve optimum use of resources in all respects (Lean's motto). This resistance should avoid causing any adverse effects on the coherence of the workplace process (i.e., without leading to depleting or endangering the HBL resources) without compromising the ability of the 
to-be situation, leading to survival or sustainable development (Rio Summit), as cited by Hartini [19]. The cost has been selected in this paper as a criterion to track the advances or setbacks of HBL elements. Lack of safety procedures is a modern type of Lean thinking that pursues to eliminate workplace waste. Therefore, positive safety culture has been deployed to help people (workers) in devoting themselves to participate in sustainable safety development by improving and controlling the influencing variables, as advocated by Andrews et al. [14]. Furthermore, there is a lack of safety metrics and adaptation of improvement methods to push enterprises' operational performance. Accordingly, pushing people to enhance their performance and systems will lead to the development of roadmaps. This paper aims to show the relationship between Lean sustainability and the safety concept via selecting the cost as a criterion measurement variable, as recommended by Kurdve [20].

Unfortunately, previous studies were conducted on the basic Triple Bottom Line (TBL) and omitted three elements of the modern world: enlightenment, oriented politics (management, planning, and strategy), and technology (e.g., process improvement tools), which contribute to maintaining sustainable development. The proposed framework is based on possessing jobs' proficiency through higher and safer performance, and understanding the subtle nuances of their jobs' implementation, by truly internalizing the reasons of risks associated with these jobs [21]. The managers give the ability to track their employees' jobs as professionals vigilantly. Proficiency is based on sensing the hazard's events. Hazard identification, containment, and correction collectively are the keystones of any safety effort. Hazard management begins with a job propounding description, which is initiated by basic skills training and continued through holistic knowledge of a process that can only come from work experience. It is essential to assess the risk of injuries, which requires sufficient data for analysis [22]. Therefore, all risks and hazards need to be collected and tracked in a local database and reviewed to look for patterns and trends that provide insights into the overall robustness of the process. To some workers, "safety is not everything, but without safety, everything nothing", which is Sakouhi's motto [23]. Therefore, a sustainable safety roadmap is an urgent issue that underpins the construction of LSPL in this study. Kumar is interested in evaluating earlier work done on sustainable lean manufacturing (SLM), which includes varied integration and correlation of variables in the industry. Researchers explained the SLM as a socioeconomic and environmental relationship. In the continuation of gaps, 97 key research papers were reviewed extensively to explore the research gap of SLM as advocated by Kumar [24]. The fifth baseline element is a policy framework (strategy) based on looking at the bigger picture (i.e., to provide deeper insight into the workplace via periodic VSM, discussed by Brown [25] and based on Ibrahim et al. [26]) that does not jeopardize any of the HBL elements, especially for people (workers). Effective incident investigation has a strong impact on injuries that may lead to a hasty conclusion qualifying the enterprises to make proactive scenarios via read-across to confront the risk of injuries in workers due to faults in their processes. Table 1 illustrates all costs' waste that must be tracked to follow the losses and faults events. Additionally, Table 2 illustrates the sustainable Lean Safety Map (LSPL) approach, which reviews the relationship between the HBL elements and their related costs accentuating the HBL due to fault opportunities. Therefore, Lean accentuates its rules' importance in diagnosing the causes of faults quickly with a direct impact on the time consumption to correct the fault and save workers' lives, reduce costs, and increase company proficiency and, ultimately, profits. This objective requires a unified framework to help in determining the starting step of risk and cause analysis quickly. Safety aims to holistic approaches create a lifestyle [27] with the message "do the right things right for the first time, every time". The implementation of a suitable framework that has been tailored to certain activities must be ensured, as argued by Yue [13] and can be inferred from Nawaz et al.'s [28] claim. This exhaustive review was conducted to illustrate the up-to-date relations among Lean's sustainability and maintenance procedures to guarantee a safer workplace by following the FCFS recommended by EsaHyytia [29]. Economic organizations are based on cost-saving heeding with developing their safety procedures and maintenance processes through renewal look to sustainability, according to Fraser [30]. Maintenance processes are some of the safety aspects that show high productivity by eliminating all non-value-added activities from their processes 
at upstream stages, as cited by Faccio et al. [31]. The two main objectives of this paper are: (1) to identify and document maintenance activities' roadmap and (2) integrate safety procedures with Lean maintenance. To reach these objectives, maintenance classifies the faults into two categories, by process or by a human based on the time consumed of reparability activities, such as corrective (i.e., after the failure occurrence) or preventive (i.e., before the failure occurrence) [31]. The purpose of the Fairbanks article is to provide an overview of resilience engineering to stimulate innovations in safety and reflect the importance more of robust tools in the application of resilience engineering are needed [32].

Table 1. Costs types manipulating in the Lean Safety Performance Level (LSPL) approach.

\begin{tabular}{|c|c|c|c|}
\hline \multicolumn{3}{|c|}{$\begin{array}{c}\text { Source: Deduced from Kaner, 1996:6 and Heizer and Render, 2001:179 Cost of Poor } \\
\text { Performance (CoPP) }\end{array}$} & \multirow{2}{*}{$\begin{array}{c}\text { HBL Investment's Elements } \\
\begin{array}{c}\text { Economical, technology } \\
\text { social }\end{array} \\
\text { Environmental, economical }\end{array}$} \\
\hline 1. Direct costs & High NNVA & $\begin{array}{l}\text { 1.1. Equipment } \\
\text { 1.2. Workers (people) } \\
\text { 1.3. Raw material } \\
\text { 1.4. Waste treatment }\end{array}$ & \\
\hline 2. Indirect costs & Moderate NNVA & $\begin{array}{l}\text { 2.1. Reporting } \\
\text { 2.2. Monitoring } \\
\text { 2.3. Regulatory (e.g., operating } \\
\text { permits and fees) }\end{array}$ & $\begin{array}{l}\text { Technology } \\
\text { Economical }\end{array}$ \\
\hline 3. Contingent Costs & Very Low NNVA & $\begin{array}{l}\text { 3.1. Liabilities } \\
\text { 3.2. Lawsuit } \\
\text { 3.3. Damage to resource } \\
\text { 3.4. Mishap/injury/accidents }\end{array}$ & $\begin{array}{l}\text { Social, economic, and policy } \\
\text { Social, economic, and } \\
\text { environmental }\end{array}$ \\
\hline 4. Internal intangible costs & Commitment NNVA & $\begin{array}{l}\text { 4.1. Company or Brand image } \\
\text { 4.2. Enterprise loyalty } \\
\text { 4.3. People (labor) morale } \\
\text { 4.4. People (labor) relations } \\
\text { 4.5. Community relations }\end{array}$ & $\begin{array}{c}\text { Social, economic } \\
\text { Policy, technology, } \\
\text { Social, enlightenment } \\
\text { Social }\end{array}$ \\
\hline \multirow{2}{*}{ 5. External intangible costs } & Customer burden & $\begin{array}{l}\text { 5.1. Handicap } \\
\text { 5.2. Depression leads to neglecting } \\
\text { 5.3. Time waste } \\
\text { 5.4. Replacement } \\
\text { 5.5. Jobless }\end{array}$ & $\begin{array}{l}\text { Social, environmental, and } \\
\text { economical }\end{array}$ \\
\hline & Enterprise burden & $\begin{array}{l}\text { 5.6. Increase of housing } \\
\text { 5.7. Reputation loss } \\
\text { 5.8. Guarantee } \\
\text { 5.9. Discounts } \\
\text { 5.10. Degradation of resources }\end{array}$ & $\begin{array}{c}\text { Economical } \\
\text { Social, economical } \\
\text { Economical }\end{array}$ \\
\hline
\end{tabular}

The paper highlights that "lack of safety precautions" must be at the forefront of the waste list. The proposed framework strives to improve processes against safety hazards and accidents; the money spent on compensation claims is a waste. Therefore, the cost element is considered the main measurement of the Lean Safety Performance Level. In recent decades, the LM (lean manufacturing) [33] system neglects human resource management as a keystone of improvement, resulting in negative consequences in industrial performance [14]. On the contrary, the strength and skill set of workers leads to industrial growth and development, according to Narkhede and Gardas [34]. Waste is the other side of "lack of safety precautions" and is determined by identifying Non-Value-Added (NVA) activities and increased engagement of tools, equipment, workers, and materials that require simplification of processes, according to Wright. Sustainability is required to meet benchmarking figures that contribute towards optimum usage and conservation of natural resources, according to Nehete et al. [35]. In the lack of safety precautions, production performance is affected by integrated manufacturing systems without control [36]. Therefore, it should be covered in a defined interval of time as recommended by Khalil [37] and Ramesh et al. [38].

LSPL, measured by FMEF $=f$ RPN (Occurrence, Severity Downtime, Detection Rate, Cost) where predicted by the NN based on some influence factors extracted from SFD. 
Table 2. Lean Safety Performance Level (LSPL) and Safety Function Deployment elements.

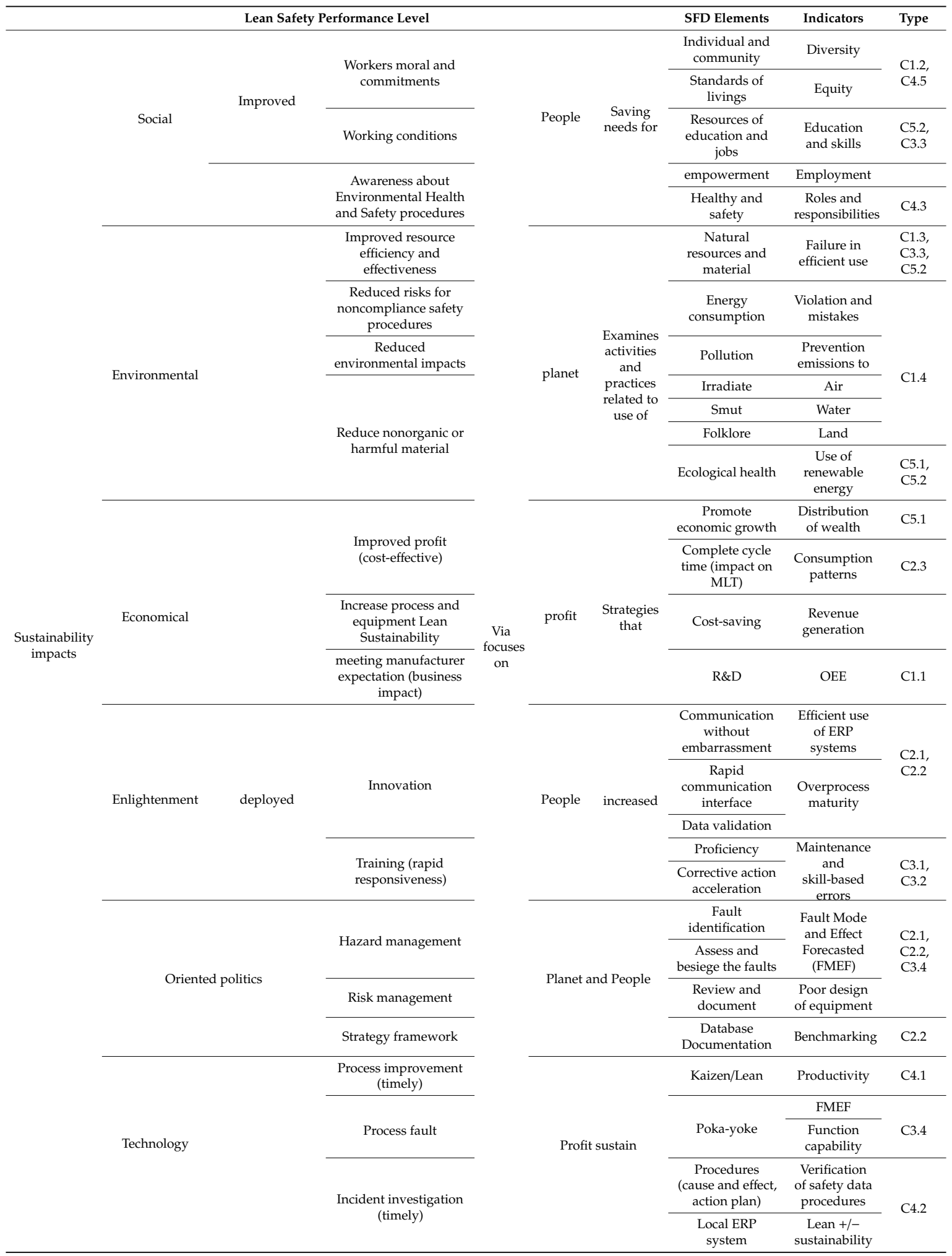

\section{The LSPL Measurement and Analysis Stages}

The LSPL is integral to the DMAIC (i.e., at Measurement and Analysis phases) that are tackled through a unified framework (i.e., consisting of sequential stages) and has many functions, as illustrated in Figure 1, related to its costs, as discussed in Tables 1 and 2, and draws on some of the Lean rules discussed in Table 3: 


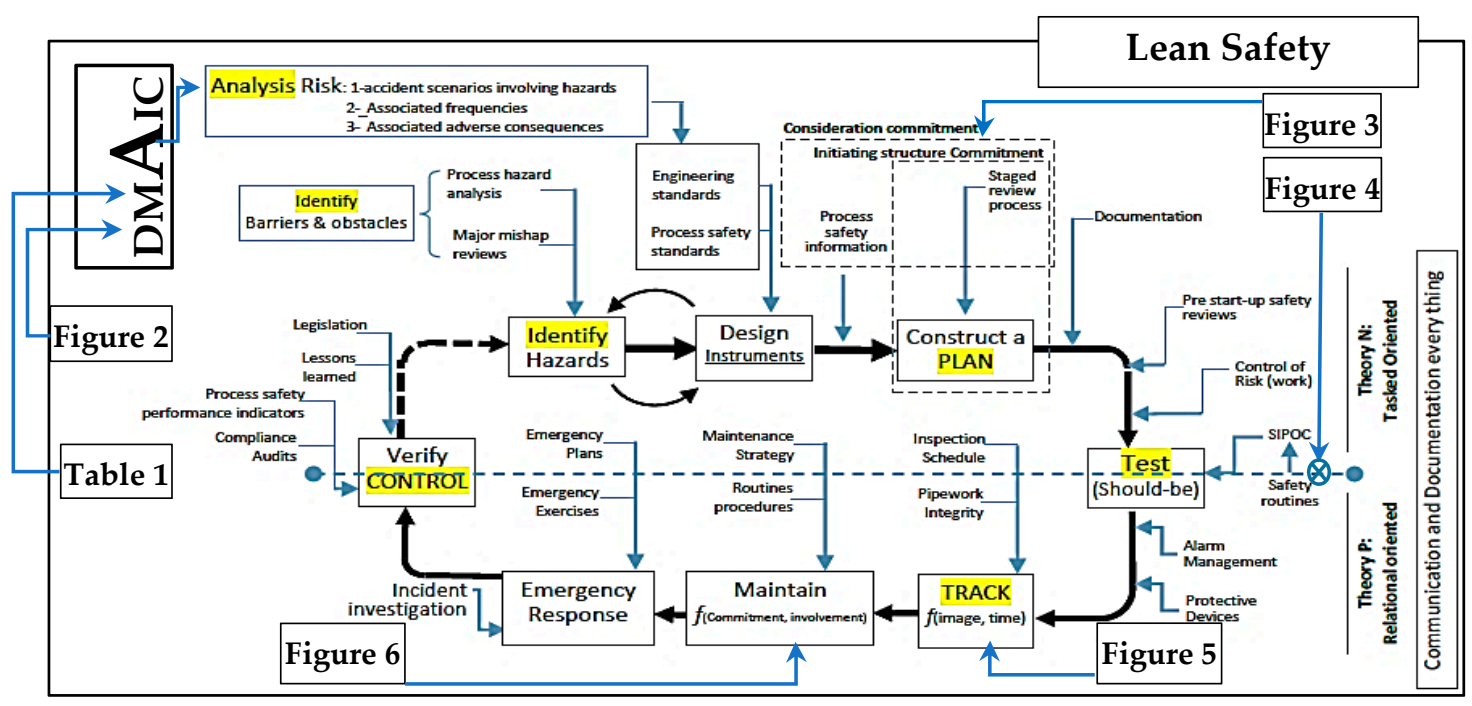

Figure 1. The LSPL Measurement and Analysis stages.

Identify: Risks that have untoward effects on HBL elements safety.

Analyze: Evaluate the probability of the risk consequences by analyzing its priority as recommended by Sumant et al. [39]. The analysis stage was quoted by Prescott et al. [40].

Plan: Plan to remove the risks, via adequate programs (i.e., proposed stages) that have a reputation to eliminate risk causes.

Test and Track: Proposed stages performance compared to the plan.

Control: Focus on understanding all risk causes throughout the proposed stages, which reveals emergent risk issues, taking into account the control action, and verify its performance.

There is a "triplet" concept of outline risk, which is useful because it clarifies how to avoid, assess, and outline risk to produce three components of risk: undesired scenarios, their probability, and their consequences. Therefore, risk $=f$ (mishap scenario, occurrence frequency, and consequence severity).

Table 3. Lean Safety Performance Level (LSPL) and their implementation tools' definition.

\begin{tabular}{|c|c|}
\hline Lean Safety Rules & Suggested Implementation Tool \\
\hline $\begin{array}{l}\text { Specifying value: Value is realized by the end-user or the next } \\
\text { requirement's step in some of the sequential processes, to meet its needs } \\
\text { at a specific cost, time, and quality, and with fewer people's efforts (i.e., } \\
\text { eliminate overprocessing) }\end{array}$ & \multirow{2}{*}{$\begin{array}{l}\text { Gemba or workplace is a Japanese term meaning "the } \\
\text { actual place", where value-creating occurs to look for } \\
\text { waste and opportunities to practice workplace kaizen } \\
\text { or practical shop-floor improvement. }\end{array}$} \\
\hline $\begin{array}{l}\text { Identify and create a value stream: In a value stream, all activities are } \\
\text { required to bring a specific goal (supplier-producer-customer). }\end{array}$ & \\
\hline $\begin{array}{l}\text { Making value flow: It flows through a Lean enterprise at the rate that } \\
\text { the next or customer needs, and just in the amount needed without } \\
\text { excess inventory. }\end{array}$ & \multirow{2}{*}{$\begin{array}{l}\text { Kanban is the name given to inventory control via } \\
\text { using a pull system, which determines the suitable } \\
\text { moving quantities in every process, between } \\
\text { upstream processes. }\end{array}$} \\
\hline $\begin{array}{l}\text { Pull not push: Only make as required. Pull the value according to the } \\
\text { end-user's demand. }\end{array}$ & \\
\hline \multirow{2}{*}{$\begin{array}{l}\text { Striving for perfection: perfection does not just mean quality. It means } \\
\text { producing exactly what the end-user wants, exactly when required. } \\
\text { Therefore, must focus on tackling six major losses: failure (1), } \\
\text { adjustment (2), minor stoppages (3), reduced operating speeds (4), } \\
\text { scrap (5), and rework (6). }\end{array}$} & $\begin{array}{l}\text { Jidoka can be defined as automation with a human } \\
\text { touch, as opposed to a device that simply moves } \\
\text { under the monitoring of an operator. }\end{array}$ \\
\hline & $\begin{array}{l}\text { OEE is defined as the effect implying, how effectively } \\
\text { planned time was used for producing good parts. }\end{array}$ \\
\hline
\end{tabular}

Table 1 shows the different elements of the cost of poor proficiency that represent Lean Safety Performance Level (LSPL) clearly and appeared in the last column of Table 2 to obtain an ideality index that helps in forecasting faults according to their cost types (direct or indirect and internal or external).

Table 2 illustrates the KPI of the proposed LSPL as recommended by the NSC at the future work section [41] and its related costs. The last column in Table 2 indicates the cost indicator types, which are 
related to the HBL elements. The LSPL aims to save the Lean implementation via some concepts discussed in Table 3.

All indicators reviewed in Table 2 are guided and tackled by using a proposed Safety Function Deployment (SFD) as mimicking to the QFD steps [42], which is based on the enterprises' expectations and safety-critical factors.

The research findings show a proven between Lean Safety and sustainability (i.e., HBL elements in a stationary and safe case), mainly because the enterprises focused on the value concept. The tools of LSPL are illustrated in Table 3, which focuses on reducing the variation of VA during its progress, by following a proven approach for gaining significant improvement in performance (DMAIC). There are five rules for implementing Lean Safety via SFD to gain desirable values as illustrated in Table 4.

Table 4. Safety Function Deployment (SFD).

\begin{tabular}{ccc}
\hline SFD Title or Process Name & \multicolumn{1}{c}{ Sustainable Safety Process (Functions), While VA/NNVA Activities } \\
\hline Ys (WHATs) & Imp. & Xs (HOWs) \\
Enterprises expectation (HBL elements) & 5 & Critical to Safety (CTS) \\
Process reliability (economic impact) & 3 & Within less than 1\% variance in process deviation \\
Timely (technological impact) & 3 & Local ERP analysis \\
Business Impact (policy and technological impact) & 4 & All corrective actions within "1" min of faults appear. \\
Rapid Responsiveness (enlightenment and social impact) & 4 & Respond to fault identification and LSPL stage cycle \\
Cost-effectiveness (economic impact) & 5 & Less expensive than the cost listed Table 1 \\
Safety procedures (social, economic, and environment impact) & 5 & 100\% inspection implementation (continuous tracking actions) aided by NN \\
\hline
\end{tabular}

The LSPL tackles safety frameworks as a remedy against a lack of implementation strategies, to present SM that stimulates the DMAIC by improving its Lean sustainability features. The LSPL focuses on pursuing radical changes in the people's enlightenment about faults classification, as illustrated in Figure 2, and its impact on HBL, thereby enhancing the profitability and urged them to improve their performance (proficiency level), the proven tool used in fault analysis is the Ishikawa or fishbone diagram.

It is used to find and derive all possible causes or root causes behind any uncertainty factor. The researchers believe that improving performance relies on forecasting mishaps via determining the famous and related causes leading to it. This diagram will be managed via the proposed reliable tool that has the ability to perform its intended objectives over a long time from the first time and every time, called Fault Mode and Effect Forecasted (FMEF).

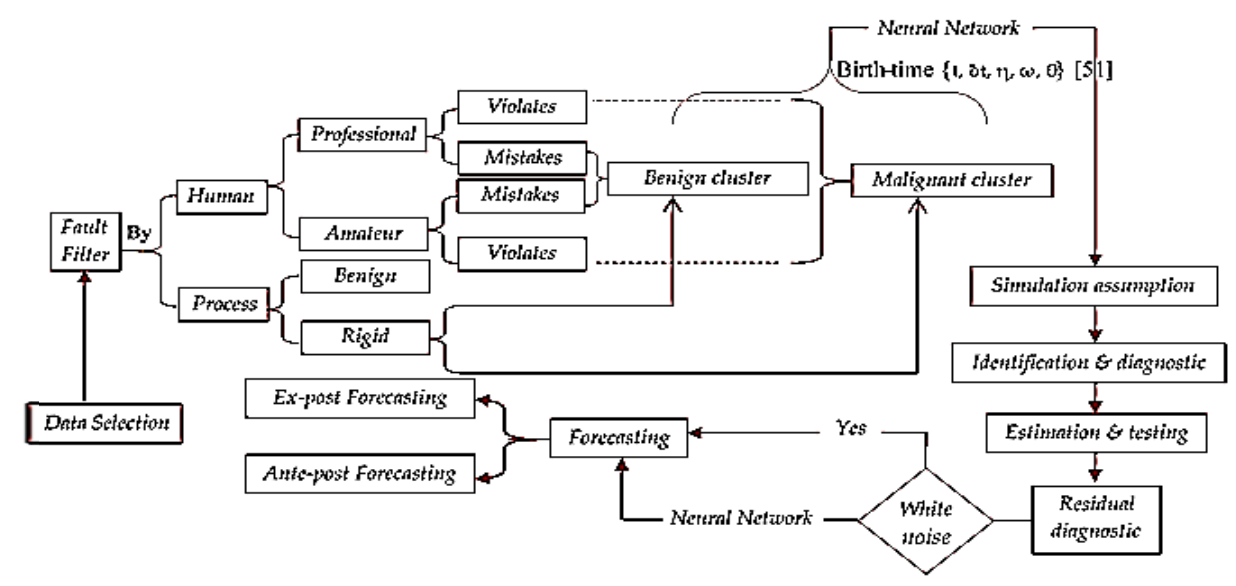

Figure 2. The conceptual classification of faults severity.

\section{Research Methodology}

This paper aims to measure the LSPL via some influencing variables according to safety considerations extracting from SFD, which is based on the ideality of each activity executed in the workplace and has a direct correlation with HBL elements vs. loss function costs based on 
the magnitude of the costs that have been spent to correct its deviation paths aided by NN model. Therefore, it is proposed to establish the House of Safety (HoS) modeled on House of Quality (HoQ), which consists of five sequential steps filled out via 185 questionnaires about tackling safety tackled. (1) monitoring all processes to maintain the deviation of processes within less than 1\%. (2) Establish a feasibility study on corrective actions for faults' causes at the moment it appeared (i.e., in time). (3) All processes uploaded and data monitored and updated via the ERP information system). (4) All faults have been identified in a tailored safety list illustrated in Figure 1. (5) Trying to be less expensive within $100 \%$ implementation of safety procedures in the enterprise. These steps were tackled through Safety Function Deployment (SFD) to extract the influencing factors, which must be forecasted and controlled as illustrated in Tables 5-8.

Step 1 of the SFD indicates the importance of LSPL in industrial society, which ranked first by $25 \%$ to the variables used to increase the safety case in the industry.

Step 2 of the SFD indicates the importance of formulating unified framework interests with the full inspection with time based on the Local ERP system analysis.

Step 3 of the SFD indicates the importance of faults' documenting throughout cycle time to maintain health and safety with respect to failure in efficient use. This target needs to construct an implementation sequential step based on valid data collected.

Step 4 of the SFD indicates the importance of statistical validation by respecting technology, especially in evaluating the equipment efficiency and the importance of proficiency value. Figure 3 discusses the dynamic process identification and using FMEA to evaluate the fault severity, while Figures 4 and 5 illustrate the flowchart of FMEF that used to track and predict the sustainable performance level via the safety tip-off of six sequential steps.

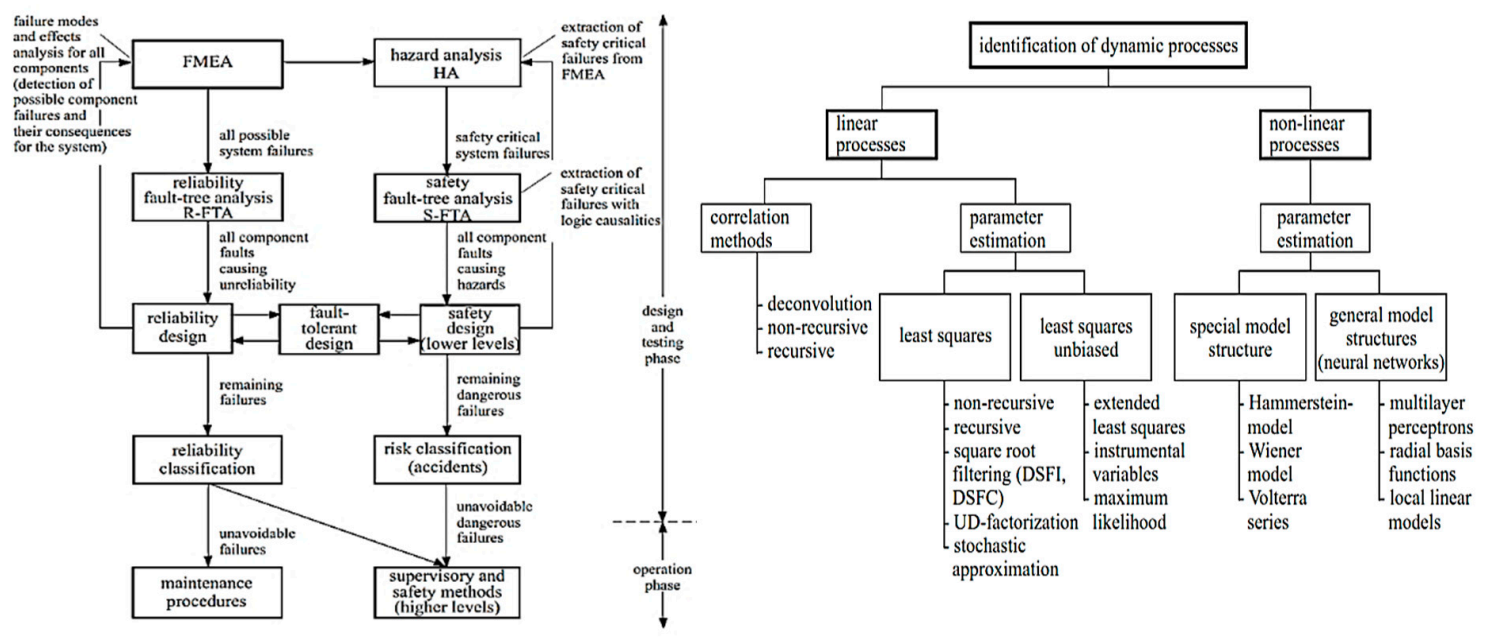

Figure 3. Framework integrating reliability and safety levels $[43,44]$.

(1) Identify the safety instructions related to Fault Modes before they happen for every Value-Added (value-added) or Non-Value-Added (NVA) activities

(2) Determines the effect and severity of these faults according to consuming time and its costs.

(3) Identifies the causes and probability of occurrence of the Fault Modes (historical data).

(4) Identifies the sustainable safety actions and their effectiveness.

(5) Quantifies and prioritizes the risks associated with the Fault Modes.

(6) Develops and documents action plans that will occur to reduce risk. 
Table 5. Safety Function Deployment (Step 1).

\begin{tabular}{|c|c|c|c|c|c|c|c|c|}
\hline & \multicolumn{8}{|c|}{ Xs (HOWs) } \\
\hline Ys (WHATs) & Importance & $\begin{array}{l}\text { Within Less than } 1 \% \\
\text { variance in process } \\
\text { deviation }\end{array}$ & $\begin{array}{c}\text { All corrective actions } \\
\text { within “ } 1 \text { " min of faults } \\
\text { appear (processes } \\
\text { deviation monitor timely) }\end{array}$ & $\begin{array}{l}\text { Local ERP } \\
\text { analysis }\end{array}$ & $\begin{array}{l}\text { Respond to fault } \\
\text { identification and } \\
\text { LSPL stage cycle }\end{array}$ & $\begin{array}{l}\text { Less expensive than } \\
\text { cost listed Table } 1\end{array}$ & $\begin{array}{c}100 \% \text { inspection } \\
\text { implementation } \\
\text { (continuous tracking } \\
\text { actions) }\end{array}$ & Total \\
\hline $\begin{array}{c}\text { Process reliability (economic } \\
\text { impact) }\end{array}$ & 5 & $\mathrm{H}$ & - & $\mathrm{H}$ & $\mathrm{M}$ & - & $\mathrm{H}$ & 150 \\
\hline Timely (technological impact) & 3 & $\mathrm{~L}$ & $\mathrm{H}$ & M & $\mathrm{H}$ & - & $\mathrm{L}$ & 66 \\
\hline $\begin{array}{l}\text { Business impact (policy and } \\
\text { technological impact) } \\
\text { Rapid responsiveness }\end{array}$ & 3 & - & L & $\mathrm{H}$ & $\mathrm{H}$ & - & M & 66 \\
\hline $\begin{array}{l}\text { (enlightenment and social } \\
\text { impact) }\end{array}$ & 4 & $\mathrm{H}$ & $\mathrm{L}$ & $\mathrm{H}$ & $\mathrm{H}$ & - & - & 112 \\
\hline $\begin{array}{l}\text { Cost-effectiveness (economic } \\
\text { impact) }\end{array}$ & 4 & - & - & $\mathrm{L}$ & M & $\mathrm{H}$ & $\mathrm{M}$ & 64 \\
\hline $\begin{array}{l}\text { Safety procedures (social, } \\
\text { economic, and environment } \\
\text { impact) }\end{array}$ & 5 & $\mathrm{H}$ & $\mathrm{H}$ & M & $\mathrm{H}$ & $\mathrm{L}$ & $\mathrm{H}$ & 195 \\
\hline Total & & 126 & 79 & 136 & 162 & 36 & 114 & 653 \\
\hline Detection weight (priority) & & $19.30 \%$ & $12.10 \%$ & $20.83 \%$ & $24.81 \%$ & $5.51 \%$ & $17.46 \%$ & \\
\hline
\end{tabular}

Table 6. Safety Function Deployment (Step 2).

\begin{tabular}{|c|c|c|c|c|c|c|c|c|c|}
\hline & & & & Xs (HOH & ) Functional Requir & & & & \\
\hline Ys (WHATs) & $\begin{array}{l}\text { Relative } \\
\text { Weight }\end{array}$ & $\begin{array}{l}\text { Complete } \\
\text { Cycle Time }\end{array}$ & $\begin{array}{l}\text { injection Fault data into } \\
\text { Local ERP system } \\
\text { (Documentation) }\end{array}$ & Data Validation & $\begin{array}{c}\text { Procedures (Cause } \\
\text { and Effect, Action } \\
\text { Plan) }\end{array}$ & $\begin{array}{l}\text { Ecological } \\
\text { health }\end{array}$ & Healthy and safety & $\begin{array}{l}\text { Efficient use of } \\
\text { ERP systems }\end{array}$ & Total \\
\hline $\begin{array}{l}\text { Respond to fault } \\
\text { identification and LSPL } \\
\text { stage cycle }\end{array}$ & 19.03 & $\mathrm{H}$ & $\mathrm{H}$ & $\mathrm{L}$ & $\mathrm{H}$ & - & $\mathrm{H}$ & - & 713.94 \\
\hline $\begin{array}{l}\text { All corrective actions } \\
\text { within " } 1 \text { " min of faults } \\
\text { appear (processes } \\
\text { deviation monitor timely) }\end{array}$ & 12.1 & $\mathrm{~L}$ & $\mathrm{~L}$ & M & $\mathrm{L}$ & - & M & & 108.88 \\
\hline Local ERP analysis & 20.83 & - & $\mathrm{M}$ & $\mathrm{L}$ & - & $\mathrm{H}$ & - & $\mathrm{M}$ & 333.23 \\
\hline $\begin{array}{l}\text { Less than } 1 \% \text { variance in } \\
\text { process deviation }\end{array}$ & 24.81 & - & $\mathrm{L}$ & $\mathrm{L}$ & - & M & - & $\mathrm{H}$ & 347.32 \\
\hline $\begin{array}{l}\text { Less expensive than cost } \\
\text { that listed Table } 1\end{array}$ & 5.51 & $\mathrm{~L}$ & $\mathrm{~L}$ & - & M & $\mathrm{L}$ & $\mathrm{L}$ & - & 38.59 \\
\hline $\begin{array}{c}100 \% \text { inspection } \\
\text { implementation } \\
\text { (continuous tracking } \\
\text { actions) }\end{array}$ & 17.46 & $\mathrm{H}$ & $\mathrm{L}$ & $\mathrm{H}$ & $\mathrm{H}$ & $\mathrm{L}$ & $\mathrm{L}$ & - & 523.74 \\
\hline Total & & 348.4 & 296.018 & 258.4 & 359.4 & 284.8 & 232.9 & 285.8 & 2065.7 \\
\hline Detection weight (priority) & & $16.87 \%$ & $14.33 \%$ & $12.51 \%$ & $17.40 \%$ & $13.79 \%$ & $11.28 \%$ & $13.83 \%$ & \\
\hline
\end{tabular}


Table 7. Safety Function Deployment (Step 3).

\begin{tabular}{|c|c|c|c|c|c|c|c|c|c|c|c|c|}
\hline & \multicolumn{12}{|c|}{ Xs (HOWs) Design Requirements } \\
\hline Ys (WHATs) & $\begin{array}{l}\text { Relative } \\
\text { Weight }\end{array}$ & $\begin{array}{l}\text { Statistical } \\
\text { validation }\end{array}$ & $\begin{array}{l}\text { Function } \\
\text { capability }\end{array}$ & $\begin{array}{c}\text { Automated } \\
\text { verification } \\
\text { of safety } \\
\text { data } \\
\text { procedures }\end{array}$ & $\begin{array}{c}\text { VA } \\
\text { capability }\end{array}$ & $\begin{array}{c}\text { Reliability } \\
+/-\end{array}$ & $\begin{array}{l}\text { Poor design } \\
\text { of equipment }\end{array}$ & OEE & $\begin{array}{l}\text { Failure in } \\
\text { Efficient use } \\
\text { FMEA }\end{array}$ & $\begin{array}{c}\text { Maintenance } \\
\text { and skill-based } \\
\text { errors } \\
\text { (proficiency) }\end{array}$ & $\begin{array}{l}\text { Roles and } \\
\text { responsibilities }\end{array}$ & Total \\
\hline $\begin{array}{l}\text { Complete cycle time } \\
\text { Injection fault data into }\end{array}$ & 12.51 & $\mathrm{H}$ & $\mathrm{H}$ & - & M & - & M & $\mathrm{H}$ & $\mathrm{H}$ & $\mathrm{H}$ & $\mathrm{L}$ & 650.4 \\
\hline $\begin{array}{l}\text { a Local ERP system } \\
\text { (documentation) }\end{array}$ & 14.33 & $\mathrm{H}$ & $\mathrm{H}$ & $\mathrm{L}$ & - & - & $\mathrm{L}$ & $\mathrm{H}$ & $\mathrm{H}$ & - & - & 544.6 \\
\hline Data validation & 16.87 & - & $\mathrm{L}$ & $\mathrm{H}$ & $\mathrm{L}$ & $\mathrm{M}$ & - & - & $\mathrm{L}$ & $\mathrm{H}$ & & 404.8 \\
\hline $\begin{array}{l}\text { Procedures (cause and } \\
\text { effect, action plan) }\end{array}$ & 17.40 & $\mathrm{~L}$ & - & M & $\mathrm{M}$ & $\mathrm{L}$ & - & - & - & - & - & 135 \\
\hline Ecological health & 13.79 & $\mathrm{~L}$ & - & - & $\mathrm{L}$ & $\mathrm{L}$ & $\mathrm{H}$ & - & $\mathrm{H}$ & - & - & 289.6 \\
\hline Healthy and safety & 11.28 & - & - & - & $\mathrm{H}$ & - & $\mathrm{H}$ & $\mathrm{H}$ & $\mathrm{L}$ & $\mathrm{H}$ & - & 417.2 \\
\hline $\begin{array}{c}\text { Efficient use of ERP } \\
\text { systems }\end{array}$ & 13.83 & - & - & - & - & - & - & M & $\mathrm{H}$ & - & $\mathrm{H}$ & 290.5 \\
\hline Total & & 272.2 & 241.53 & 64.93 & 203.4 & 30.65 & 277.4 & 384.5 & 501.4 & 214 & 137. & 2327.1 \\
\hline $\begin{array}{l}\text { Detection weight } \\
\text { (priority) }\end{array}$ & & $11.7 \%$ & $10.4 \%$ & $2.8 \%$ & $8.7 \%$ & $1.3 \%$ & $11.9 \%$ & $16.5 \%$ & $21.5 \%$ & $9.2 \%$ & $5.9 \%$ & \\
\hline
\end{tabular}

Table 8. Safety Function Deployment (Step 4).

\begin{tabular}{|c|c|c|c|c|c|c|c|c|}
\hline \multirow[b]{2}{*}{ Ys (WHATs) } & \multicolumn{8}{|c|}{ Xs (HOWs) Key Process Variables } \\
\hline & Relative Weight & Social/People & Environmental & Economic/profit & Enlightenment & Oriented politics & Technology & Total \\
\hline Statistical validation & 11.7 & $\mathrm{H}$ & $\mathrm{H}$ & $\mathrm{L}$ & $\mathrm{M}$ & - & $\mathrm{L}$ & 269.02 \\
\hline Function capability & 10.38 & - & $\mathrm{H}$ & - & - & - & $\mathrm{H}$ & 186.82 \\
\hline $\begin{array}{l}\text { Automated verification of safety data } \\
\text { procedures }\end{array}$ & 2.79 & - & $\mathrm{M}$ & - & $\mathrm{L}$ & $\mathrm{H}$ & $\mathrm{L}$ & 39.1 \\
\hline VA capability & 8.74 & $\mathrm{M}$ & $\mathrm{L}$ & - & $\mathrm{H}$ & - & - & 113.62 \\
\hline Reliability $+/-$ & 1.317 & - & - & $\mathrm{H}$ & & $\mathrm{M}$ & $\mathrm{H}$ & 27.66 \\
\hline Poor design of equipment & 11.92 & - & - & & $\mathrm{L}$ & $\mathrm{H}$ & $\mathrm{L}$ & 131.14 \\
\hline OEE & 16.5 & - & $\mathrm{M}$ & $\mathrm{H}$ & $\mathrm{M}$ & - & $\mathrm{M}$ & 297.42 \\
\hline $\begin{array}{l}\text { Maintenance and skill-based errors } \\
\text { (proficiency) }\end{array}$ & 21.55 & L & $\mathrm{H}$ & $\mathrm{H}$ & $\mathrm{L}$ & - & M & 211.55 \\
\hline Failure in efficient use FMEA & 9.20 & - & - & - & - & M & $\mathrm{H}$ & 258.56 \\
\hline Roles and responsibilities & 5.89 & $\mathrm{H}$ & - & - & M & $\mathrm{H}$ & $\mathrm{H}$ & 176.63 \\
\hline Total & & 193.67 & 348.1 & 255 & 204.9 & 254 & 455.75 & 1711.48 \\
\hline Detection weight (priority) & & $11 \%$ & $20 \%$ & $15 \%$ & $12 \%$ & $14 \%$ & $27 \%$ & \\
\hline
\end{tabular}




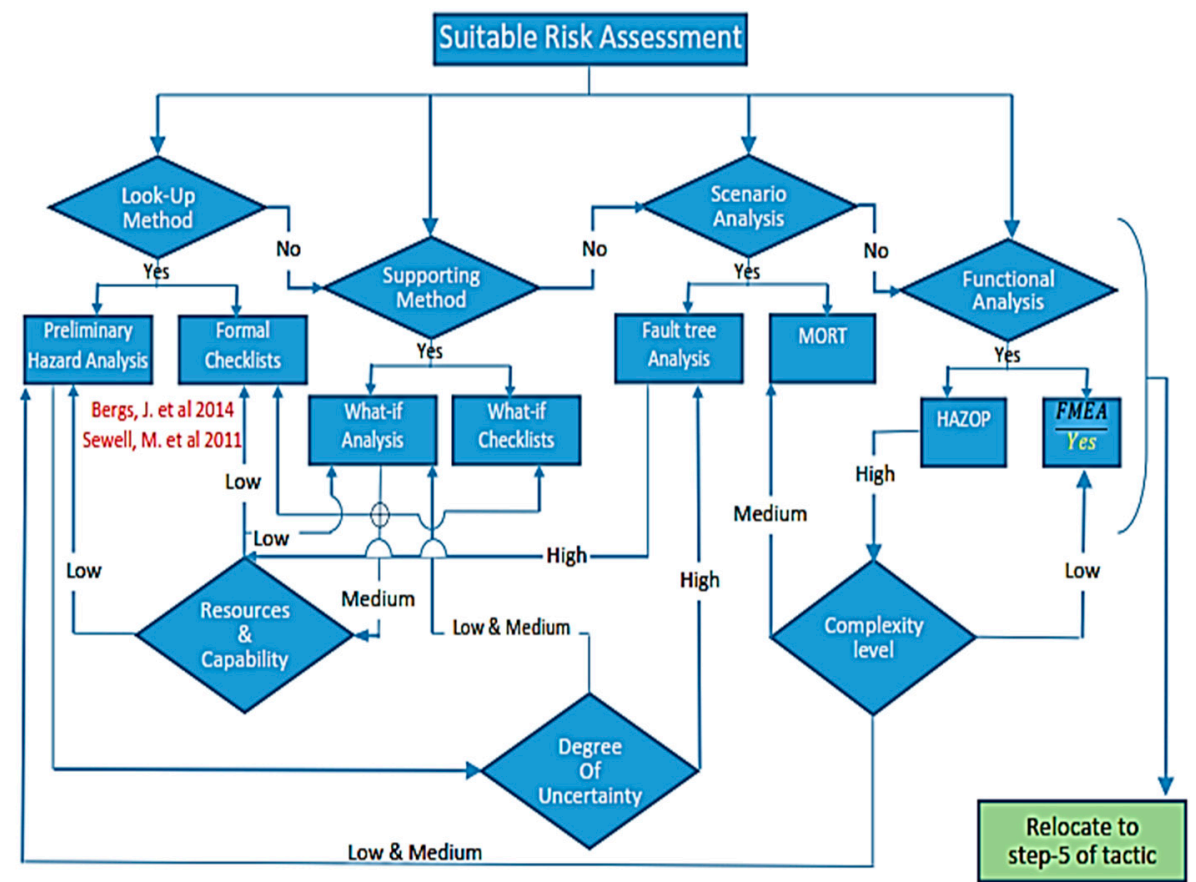

Figure 4. Select suitable risk assessment to risk investigation.

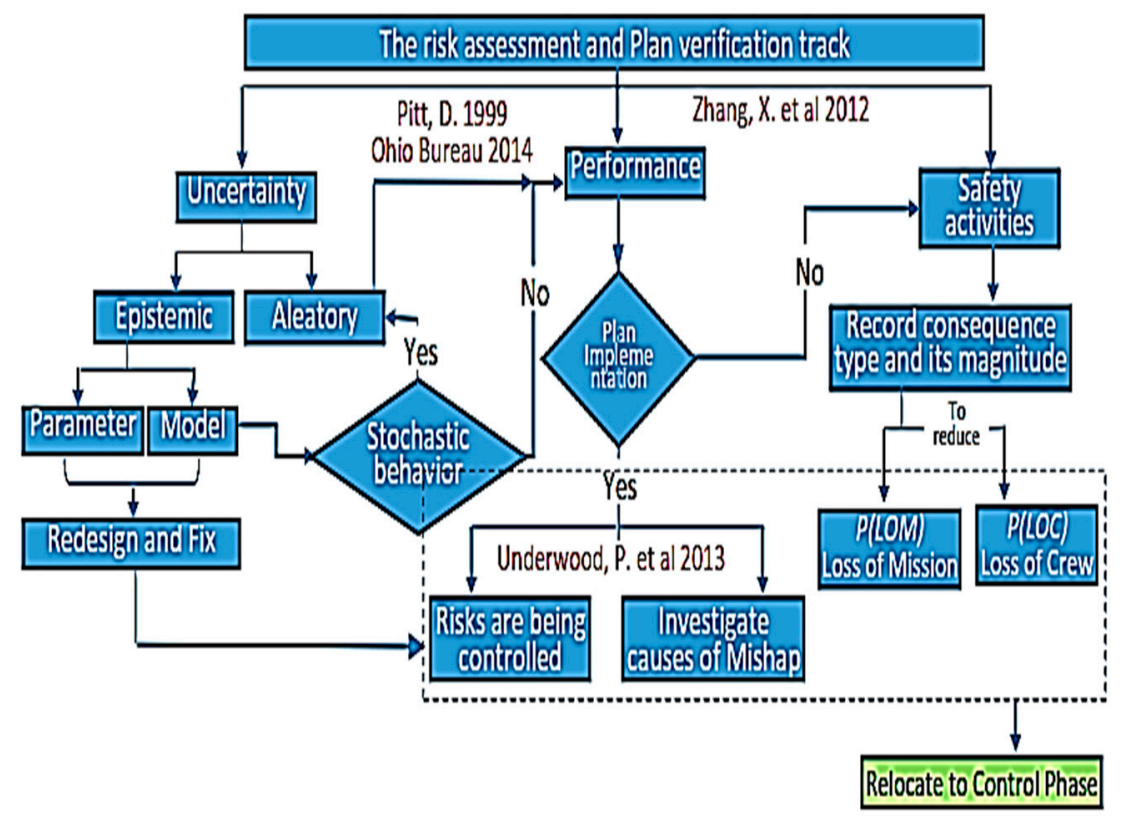

Figure 5. Track the plan phase activities in the proposed LSPL stages.

A preliminary stage of adopting (undertaking) LSPL embeds a sustainability constraint to ass the identification and prioritization with respect to modern HBL and the common Lean Six Sigma (LSS) tools are exposed in Table 9. 
Table 9. The common tools between Lean Six Sigma (LSS) and the proposed LSPL.

\begin{tabular}{|c|c|c|c|c|c|c|}
\hline \multicolumn{7}{|c|}{ Lean Six Sigma (LSS) Roadmap } \\
\hline & & Define and Measures & & & Improve & Control \\
\hline \multirow{10}{*}{$\begin{array}{l}\text { Lean Safety } \\
\text { Performance } \\
\text { Level (LSPL) }\end{array}$} & Identify & Project charter & VSM & $\begin{array}{l}\text { Spaghetti } \\
\text { diagram for } \\
\text { functions }\end{array}$ & Poka-Yoke & $\begin{array}{l}\text { Proficiency } \\
\text { level }\end{array}$ \\
\hline & \multirow{2}{*}{ Analysis } & \multirow{3}{*}{$\begin{array}{l}\text { Function/process/activities } \\
\text { map }\end{array}$} & \multirow{3}{*}{ Run charts } & \multirow{3}{*}{$\begin{array}{l}\text { Regression } \\
\text { analysis }\end{array}$} & Risk analysis & Dashboard \\
\hline & & & & & \multirow[t]{2}{*}{$\begin{array}{l}\text { Prioritization } \\
\text { matrix }\end{array}$} & \multirow[t]{2}{*}{ Audit plans } \\
\hline & Plan & & & & & \\
\hline & Track & \multirow{2}{*}{ Critical to poor safety tree } & KPI & \multirow{2}{*}{$\begin{array}{l}\text { ANOVA to } \\
\text { DOE }\end{array}$} & $6^{\prime} \mathrm{S}$ & $\begin{array}{l}\text { Performance } \\
\text { management }\end{array}$ \\
\hline & Control & & $\begin{array}{l}\text { Process } \\
\text { capability }\end{array}$ & & FMEF & \\
\hline & & SIPOC & Histograms & $5^{\prime}$ Why & FMEA & \\
\hline & \multicolumn{2}{|c|}{ Critical to quality tree } & \multicolumn{2}{|c|}{ Management system analysis } & \multicolumn{2}{|c|}{ Embedding sustainability } \\
\hline & \multicolumn{4}{|c|}{ House of Quality } & & \\
\hline & \multicolumn{4}{|c|}{ Kano analysis } & & \\
\hline
\end{tabular}

\section{Failure Mode and Effect Forecasting (FMEF) Formulation}

Sustainable Lean is equivalent to system reliability $R(t)$ against fault occurrence, availability, and maintainability, which are important factors to guarantee the safety level. Sustainable Lean is affected by faults and malfunctions occur in the workplace. Therefore, the prediction and diagnosis of the faults are the core of this paper. Faults related to deviation behavior according to their form whether systematic or random, time behavior appears from draft to permanent path through noise and extent appears in local or global VSM. The Lean sustainability of many identical activities is defined by Equation (1).

$$
\text { Fault Occurrence }=1-R(t)=\omega=1-\frac{\text { fault free activities }}{\text { number of all activities at a certain function }}
$$

The fault occurrence rate defined as the instantaneous rate of malfunction or unplanned downtime at emergency case is defined by the Equation (2):

$$
\frac{d_{n}}{d_{t}}=\lambda_{t}=\frac{1}{\# \text { of function activities }}\left(\frac{\# \text { of faults }}{\text { time interval }}\right)
$$

The severity $S_{v}$ level proportion to a maintenance level (the repairability consuming time), whether planned or not as illustrated in Figure 6 to repair specific fault, is defined by the Equation (3) as follows:

$$
S_{v}=E\left\{T_{R}\right\}=\lim _{N \rightarrow \infty} \frac{1}{N} \sum_{i=1}^{N} T_{R i}
$$

where $T_{R i}$ is time to repair the malfunction. 


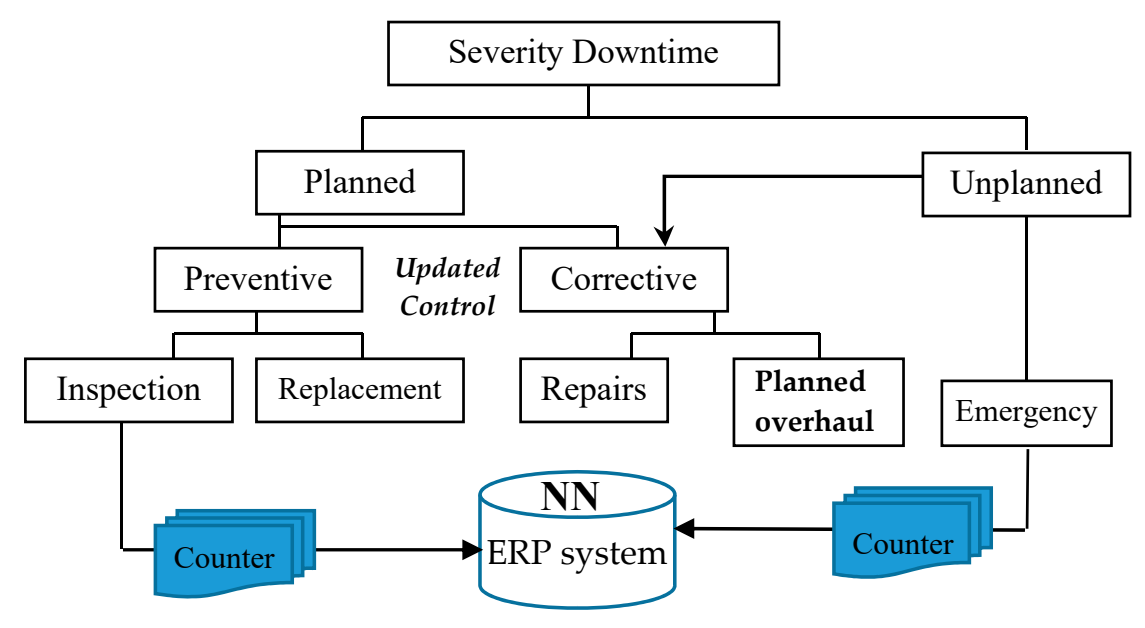

Figure 6. The types of maintenance causes.

The concept of Ideality is introduced in the methodology of creative problem solving, which is very close to the value in value analysis. One variant is known as the "Theory of Inventive Problem Solving". While stipulating that a proposed framework has the main "VA activity function".

The delivery of it is necessarily accompanied by loss functions (i.e., NNVA and NVA costs and time) that can be controlled via the proposed roadmap embeds with an effective framework. The better is the framework the fewer are the number of the loss functions (i.e., any undesired costs or downtimes) that addressed via ideality index_P $P y_{i_{-}}$as defined by the Equation (4). This value is considered a seed of using the Neural Networks of the optimization stage of fault tracking and forecasting based on specific scenarios (i).

$$
P y_{i}=\frac{\mathrm{RPN} \times \sum_{i}(\mathrm{VA})_{i}}{\sum_{i}(\mathrm{NNVA})_{i}+(\mathrm{NVA})_{i}}=\frac{\sum_{i}\left(\mathrm{VA}_{\text {Costs, time }}\right)_{i}}{\sum_{i}\left(\mathrm{NNVA}_{\text {Costs, time }}\right)_{i}}=\frac{\mathrm{RPN} \times \sum_{i}\left(\mathrm{VA}_{\text {Costs, time }}\right)_{i}}{\sum_{i}(\mathrm{CoPP})_{i}}
$$

The question should be: how to execute the VA in a way that is not minimalist (NNVA). An Ideality defined by Equation (5) indicates the effectiveness of the proposed framework is calculated using the ratio of the number of valid causes to the total number of potential causes and averaged over the tackling scenarios for data collected in Tables 9 and 10.

$$
\operatorname{Ideality}\left(\mathrm{HBL}_{V A}\right)_{i}=\frac{1}{N} \sum_{i=1}^{i} \frac{P y_{i}}{C_{i} \times n_{i}} \times w_{i}
$$

where

$N=$ number of correction scenarios investigated to reduce losses and faults opportunities in certain activity.

$n_{i}=$ number of potential causes of malfunction due to fault identified by the framework for scenario $i$. $C_{i}=$ cost of potential causes of malfunction due to fault identified by the framework for scenario $i$.

$w_{i}=$ weight of potential causes of malfunction under scenario $I$ consideration extracted from SFD result in Table 8 (Step 4).

Ideality $_{i}=$ number of correct potential causes of malfunctions due to fault obtained by the framework for scenario $i$. 
Table 10. FMEF terminology suggestion.

(1) Fault Opportunities: (Specific loss of any of HBL functions), related to opportunities aforementioned in Table 1.

(2) Fault mode "effect": A description of the consequence and ramification of any HBL faults, to rank these faults according to a severity scale. A typical Fault Mode may have several "effects" depending on a review of which manufacturer, manufacturer, or any of stakeholders are considered (i.e., analyzed and tailored according to needs via brainstorming recommendations).

(4) Fault mode "causes": A description of the proficiency' losses (high ramifications of direct and root causes) that results in the Fault Mode, which can be formulated via classical cause and effect diagram.
(3) Severity rating $\eta$ : (seriousness of the effect) Severity is the numerical rating (e.g., 1:10) of the impact on customers, manufacturer or any of HBL elements, related with loss function (i.e., nonideality, which use expenses indicator as a costs' reference estimated according to Table 1). Severity against the maintainability level or mean time to repair the fault MTTR.

(5) Occurrence rating $\omega$ : An estimated number of tenfold relative frequencies of the cumulative number of specific causes over the intended period

"threatening the sustainability of the safety case" (i.e., frequency codification and tracked out via mining in the local dataset).

This step needs for creating a time schedule for predicted faults and codify via closely monitoring its behavior at a specified period using any of forecasting procedures, such as ARIMA or using the codes of artificial intelligent as Neural Network (e.g., time of the birth of the fault: $t$, fault's lifespan: $\delta t$, severity: $\eta$, occurrence: $\omega$ and loss cost estimations: $\theta$ )

(6) Fault Mode "(safety investigation)": The methods, tests, procedures, or controls used to prevent the cause of the Fault Mode or detect the Fault Mode or cause should it occur.
(7) Detection rating (forecasted via ARIMA) [45]: A numerical rating (i.e., 1:10, 1 being detectable via forecasting every time, 10 being impossible to detect via forecasting) of the probability that a given set of the investigation will discover a specific cause of Fault Mode to resist consequences.

(8) Risk Priority Number (RPN; descending Order): $=\mathrm{S}_{\text {everity }} \times \mathrm{O}_{\text {ccurrence }} \times \mathrm{D}_{\text {etecting }}$ is a response

(9) Action planning: A high-risk framework that is not followed with corrective actions has little or no value, other than having a chart for an audit. Therefore, the FMEF is created. If ignored, you have probably wasted much of your valuable time. A good action plan focused on reducing the RPN by adopting the obvious safety roadmap has many VA functions.

The main result of the design stage of the proposed LSPL framework is to obtain RPN from FMEF steps and record it in time to calculate the consuming repair time and document that with its expenses deduced from Table 1.

\section{Lean Safety Performance Level (LSPL) Case Study}

The costs and consuming maintainability time were classified according to Tables 1 and 2. The experts according to questionnaire analysis decided that the performance level should be among $65 \%$ to $99.9 \%$ [46], and distributed according to the illustration Table 11 . The proposed LSPL framework stages were adopted via U.S.C.C (a consultant office owned by Zagazig University, Egypt). The losses and costs data for the medium and small industrial organization's scale has been collected from 495 departments belongs 18 ERP's enterprise systems of different industries from July 2014 to November 2019 in some industrial Egyptian cities through physical visits and the online questionnaires that oriented to the safety's managers who participated in this survey voluntarily.

Table 11. The Lean Safety Performance Level reference [47].

\begin{tabular}{|c|c|c|c|c|c|}
\hline Limits & $60-70 \%$ & $>70-80 \%$ & $>80-94 \%$ & $>94-96 \%$ & $>96-99.999996 \%$ \\
\hline Risk level & Under Risk & Moderate & Adequate & Near Safe & Completely Safe \\
\hline
\end{tabular}


The influencing measurement variables for the planning (i.e., Measuring and Analysis) for the Lean Safety LSPL framework as illustrated in Table 12. These variables have been tackled as illustrated in Table 13, which are related to HBL abuses.

Table 12. Questionnaire outlines that activate the LSPL framework stages.

\begin{tabular}{|c|c|}
\hline LSPL Stages & Influencing Requirements \\
\hline Identify and Planning Stage & $\begin{array}{c}\text { IPS1: Prevention plan safety deployment among all workers } \\
\text { IPS2: Identify risks in all manufacturing processes stations } \\
\text { IPS3: Work procedures based on risk standard evaluation } \\
\text { IPS4: Respect the periodic checks of prevention activities execution and compliance with } \\
\text { regulations } \\
\text { IPS5: Ensuring that all risks are measured their severity, investigated, analyzed, and } \\
\text { documented }\end{array}$ \\
\hline Design Stage Instruments & $\begin{array}{l}\text { DSI1: Control the impact of our manufacturing processes on safety } \\
\text { DSI2: A systematic framework to identify the safety targets } \\
\text { DSI3: A systematic framework to achieve the safety targets } \\
\text { DSI4: A systematic framework to demonstrate that safety targets have been met } \\
\text { DSI5: Control Lean influencing of manufacturing processes } \\
\text { DSI6: A systematic framework to adjust and achieve the Lean targets } \\
\text { DSI7: A systematic framework to demonstrating that Lean targets have been met }\end{array}$ \\
\hline Tracking and Test Stage & $\begin{array}{c}\text { TaTS1: The occurrence scale of accidents at the participated enterprises } \\
\text { TaTS2: Lean's health and safety long-term precautions at participated enterprises } \\
\text { TaTS3: Energy and water consumptions in participating enterprises } \\
\text { TaTS4: Waste reutilization at participating enterprises }\end{array}$ \\
\hline $\begin{array}{l}\text { Work safety and Control } \\
\text { Performance }\end{array}$ & $\begin{array}{l}\text { WSCP1: Reduced the number of incidents at participating enterprises } \\
\text { WSCP 2: Reduced the number of injuries at participating enterprises } \\
\text { WSCP 3: Reduced the number of ill health at participating enterprises } \\
\text { WSCP 4: Reduced the number of insurance claims at participating enterprises }\end{array}$ \\
\hline $\begin{array}{l}\text { Expected Lean } \\
\text { Performance }\end{array}$ & $\begin{array}{l}\text { ELP1: Reduced losses costs at participating enterprises (review Table 1) } \\
\text { ELP2: Reduced the NNVA Occurrence Rating } \omega \text { in participating enterprises (review Table } 10 \\
\text { and Equation (1)) } \\
\text { ELP3: Reduced the NNVA Severity Rating } \eta \text { level in participating enterprises (review Table 10) } \\
\text { ELP4: Increased the ideality value (review Equation (4)) to deploy the performance } \\
\text { level/monthly } \\
\text { ELP5: Measure the cost of poor proficiency that generated due to NNVA faults to be controlled }\end{array}$ \\
\hline
\end{tabular}

Out of 495 questionnaires, $197(40.2 \%)$ responses were received. Incomplete questionnaires were discarded. The final study sample consisted of 185 (37.7\%) valid returned questionnaires that were implemented in different 18 enterprises. The characteristics summarized of the respondent's enterprises indicate that the majority of them are cartons' industries $(48.3 \%)$, metal industry $(19.1 \%)$, textile industries (15.4\%), bathtubs fabrications (9.4\%), electronics and other electrical equipment $(4.2 \%)$, and others factories represent (3.4\%). Reliability has been tested based on Cronbach's alpha value illustrated in Table 13. For the reliability test, Cronbach's alpha value for safety precautions activities performance had the highest (0.936) while the Lean performance was the lowest $(0.861)$. Thus, all of the Cronbach's alpha values (extracted from $R$ statistical software) were significant at $p<0.05$.

The principal component analysis (PCA) and the confirmatory factor analysis (CFA) used to identify the most meaningful basis and to check the similarities and differences of the data validation. Eigenvalues and percent of variance explained for each stage at the LSPL framework are illustrated for 185 enterprises' sectors interests in the implementation of LSPL, and the cumulative percentages of explained variance were 66.509 for the stages illustrated in Table 13. The loading values of each influence variable ranged from 0.619 to 0.889 as illustrated in Table 13 and deduced from SFD (Table 8, Step 4). However, all variables that appeared at any stage of Table 12, and had a loading value less than 0.5 , were removed from the implementation illustrated in Table 14.

The recorded "102,592" activities for a VA and NNVA of one from participated enterprises from July 2014 to November 2019 are around the whole safety practices illustrated in Table 14, which illustrates the costs related with potential incidents or injuries (i.e., The cost is the summation of maintainability costs plus the cost of consuming downtime associated with fault opportunity). There are some questions to be answered to determine the performance level of implemented LSPL. These questions are listed below : 
1. How many Fault occurrences for a single function? (19).

2. How much is the enterprise cost on Faults identified? (3041.13).

3. How much is the average cost of faults per function? $(3041.13 / 102,592=0.0296)$.

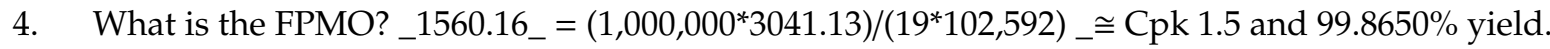

5. What is the (approximate) LSPL for LSPL implementation? (4.5 marks over $6(75 \%)$ ).

Table 13. Results of principal component analysis (PCA) and confirmatory factor analysis (CFA) for LSPL framework validations.

\begin{tabular}{|c|c|c|c|c|c|c|c|c|}
\hline \multirow{2}{*}{\multicolumn{2}{|c|}{$\begin{array}{l}\text { Questions Outlines of LSPL } \\
\text { Variables Stages }\end{array}$}} & \multirow[b]{2}{*}{ Eigenvalue } & \multirow{2}{*}{$\begin{array}{c}\text { PCA } \\
\text { Percent of } \\
\text { Variance } \\
\text { Explained }\end{array}$} & \multicolumn{5}{|c|}{ CFA } \\
\hline & & & & $\begin{array}{l}\text { Variables } \\
\text { Loading }\end{array}$ & $\begin{array}{l}\text { Expected } \\
\text { Loading }\end{array}$ & $t$-Value & $p$-Value & $\begin{array}{l}\text { Cronbach's } \\
\text { Alphas }\end{array}$ \\
\hline \multirow{5}{*}{$\begin{array}{l}\text { Identify and } \\
\text { planning stage }\end{array}$} & IPS 1 & \multirow{5}{*}{2.901} & \multirow{5}{*}{8.431} & 0.795 & 0.861 & 15.111 & 0.000 & \multirow{5}{*}{0.904} \\
\hline & IPS 2 & & & 0.862 & 0.923 & 16.610 & 0.000 & \\
\hline & IPS 3 & & & 0.885 & 0.958 & 17.744 & 0.000 & \\
\hline & IPS 4 & & & 0.876 & 0.930 & 16.839 & 0.000 & \\
\hline & IPS 5 & & & 0.794 & 0.822 & - & - & \\
\hline \multirow{7}{*}{$\begin{array}{l}\text { Design stage } \\
\text { instruments }\end{array}$} & DSI 1 & \multirow{7}{*}{13.079} & \multirow{7}{*}{43.502} & 0.727 & 0.709 & 10.953 & 0.000 & \multirow{7}{*}{0.897} \\
\hline & DSI 2 & & & 0.689 & 0.675 & 10.247 & 0.000 & \\
\hline & DSI 3 & & & 0.478 & 0.496 & 10.670 & 0.000 & \\
\hline & DSI 4 & & & 0.717 & 0.879 & 15.074 & 0.000 & \\
\hline & DSI 5 & & & 0.734 & 0.838 & 13.999 & 0.000 & \\
\hline & DSI 6 & & & 0.742 & 0.862 & 18.382 & 0.000 & \\
\hline & DSI 7 & & & 0.760 & 0.841 & - & - & \\
\hline \multirow{4}{*}{$\begin{array}{l}\text { Tracking and } \\
\text { test stage }\end{array}$} & TaTS 1 & \multirow{4}{*}{1.936} & \multirow{4}{*}{8.412} & 0.619 & 0.755 & 13.079 & 0.000 & \multirow{4}{*}{0.899} \\
\hline & TaTS 2 & & & 0.637 & 0.783 & 13.722 & 0.000 & \\
\hline & TaTS 3 & & & 0.741 & 0.778 & 10.824 & 0.000 & \\
\hline & TaTS 4 & & & 0.818 & 0.754 & 12.696 & 0.000 & \\
\hline \multirow{4}{*}{$\begin{array}{l}\text { Work safety } \\
\text { and control } \\
\text { performance }\end{array}$} & WSCP 1 & \multirow{4}{*}{1.596} & \multirow{4}{*}{3.339} & 0.822 & 0.913 & 22.445 & 0.000 & \multirow{4}{*}{0.936} \\
\hline & WSCP 2 & & & 0.832 & 0.944 & 24.953 & 0.000 & \\
\hline & WSCP 3 & & & 0.817 & 0.935 & 24.140 & 0.000 & \\
\hline & WSCP 4 & & & 0.829 & 0.929 & - & 0.000 & \\
\hline \multirow{5}{*}{$\begin{array}{l}\text { Expected Lean } \\
\text { performance }\end{array}$} & ELP 1 & \multirow{5}{*}{1.148} & \multirow{5}{*}{2.825} & 0.741 & 0.774 & 11.492 & 0.000 & \multirow{5}{*}{0.861} \\
\hline & ELP 2 & & & 0.840 & 0.864 & 13.204 & 0.000 & \\
\hline & ELP 3: & & & 0.848 & 0.884 & 13.565 & 0.000 & \\
\hline & ELP 4 & & & 0.841 & 0.872 & 13.214 & 0.000 & \\
\hline & ELP 5 & & & 0.871 & 0.863 & - & - & \\
\hline
\end{tabular}

Table 14. Recording the downtimes of violating the LSPL instructions and its related costs.

\begin{tabular}{|c|c|c|c|c|c|c|c|c|c|}
\hline $\begin{array}{c}\text { Fault } \\
\text { Opportunity }\end{array}$ & Cost Type (\$) & $7 / 2014$ & $10 /^{2015}$ & $3 / 2016$ & $8 /^{2017}$ & $1 / /^{2018}$ & $11 / /^{2019}$ & Time (h) & Ideality \\
\hline IPS 1 & C1.1, C5.1 & 168 & 346 & 224 & 321 & 153 & 113 & 220.83 & 0.22 \\
\hline IPS 2 & $\mathrm{C} 1.2, \mathrm{C} 2.2$ & 474 & 279 & 34 & 37 & 82 & 71 & 162.83 & 0.16 \\
\hline IPS 3 & \multirow{2}{*}{ C1.1, C3.3 = \$3871 for example } & 757.2 & 284.1 & 168.9 & 129 & 173 & 114 & 271.03 & 0.27 \\
\hline IPS 4 & & 453 & 493 & 117 & 229 & 86 & 18 & 232.67 & 0.23 \\
\hline IPS 5 & C1.4 & 318 & 49 & 129.6 & 196 & 24 & 19 & 122.6 & 0.12 \\
\hline TaTS 1 & $\mathrm{C} 1.3, \mathrm{C} 1.4$ & 432 & 208 & 139 & 313 & 613 & 128 & 305.5 & 0.35 \\
\hline TaTS 2 & C2.1 & 483 & 284 & 125 & 169 & 287 & 69 & 236.17 & 0.21 \\
\hline TaTS 3 & \multirow{2}{*}{$\mathrm{C} 1.3, \mathrm{C} 1.4, \mathrm{C} 5.10$} & 21 & 552 & 106 & 328 & 183 & 71 & 210.17 & 0.20 \\
\hline TaTS 4 & & 345 & 413 & 148 & 663 & 74 & 55 & 283 & 0.28 \\
\hline DSI 1 & \multirow{6}{*}{ C1.1, C2.3, C3.1, C3.3, C5.7 } & 252 & 305 & 24 & 64 & 2 & 157 & 134 & 0.135 \\
\hline DSI 2 & & 6 & 17 & 41 & 110 & 244 & 18 & 72.67 & 0.073 \\
\hline DSI 4 & & 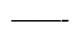 & 100 & - & - & 15 & 61 & 29.33 & 0.029 \\
\hline DSI 5 & & 135 & 51 & - & 35 & - & 61 & 47 & 0.047 \\
\hline DSI 6 & & 438 & 54 & 89 & 78 & 30 & 15 & 117.33 & 0.12 \\
\hline DSI 7 & & 348 & 33 & 18 & 55 & 66 & 13 & 88.83 & 0.089 \\
\hline WSCP 1 & $\mathrm{C} 1.4, \mathrm{C} 3.1, \mathrm{C} 3.4$ & 150 & 22 & 57 & 253 & 187 & 143 & 135.33 & 0.136 \\
\hline WSCP 2 & $\mathrm{C} 4.3, \mathrm{C} 4.4$ & 655 & 33 & 115 & 40 & 52 & 57 & 158.67 & 0.15 \\
\hline WSCP 3 & C 3.2 & 78 & 1 & 108 & 135 & 47 & 4 & 62.17 & 0.06 \\
\hline WSCP 4 & C4.2, C4.5, C5.9 & 516 & 56 & 87 & 39 & 105 & 103 & 151 & 0.151 \\
\hline \multicolumn{8}{|c|}{ Total consumed downtime and costs of poor proficiency } & 3041.1 & \\
\hline
\end{tabular}

The decision: This industry is in a moderate risk situation according to Table 11. 
The main issue from implementing the proposed framework is finding a safety scale for different industries modeled on the defect scale that is named by DPMO tables. The last two columns in Table 14 illustrate the consumption of repair time and the ideality according to cost types appeared in the second column of the same table according to a specific case study. The performance of the enterprises in following and implementing special instruction recommended by the LSPL stages is an audit by ideality multiple by the time consumption of the repairing activities (i.e., downtime), which is considered a representative point for the enterprise evaluation according to this variable and start tracking it via using NN. The non-proficiency/year (faults) are illustrated in Table 15.

Table 15. Non-proficiency/year (faults) due to the 102,592 maintainability process for 18 enterprises.

\begin{tabular}{|c|c|c|c|c|c|c|c|c|c|c|c|}
\hline \multirow{3}{*}{$\begin{array}{l}\text { Former } \\
\text { Year }\end{array}$} & \multicolumn{2}{|c|}{$\begin{array}{l}\text { Vacuum Pump } \\
\text { Malfunction }\end{array}$} & \multicolumn{2}{|c|}{$\begin{array}{c}\text { Blockage in Air } \\
\text { Stream }\end{array}$} & \multicolumn{2}{|c|}{ Air Cavity Close } & \multicolumn{2}{|c|}{ Damage Cavity } & \multicolumn{2}{|c|}{$\begin{array}{c}\text { Incomplete Air } \\
\text { Conduit }\end{array}$} & \\
\hline & Incident & injury & Incident & injury & Incident & injury & Incident & injury & Incident & injury & \\
\hline & 28 & 35 & 32 & 12 & 36 & 21 & 38 & 32 & 38 & 35 & \\
\hline 2014 & 23 & 29 & 19 & 3 & 17 & 10 & 15 & 12 & 1 & 3 & \\
\hline 2015 & 4 & 24 & 4 & 14 & 25 & 4 & 1 & 4 & 1 & 5 & \\
\hline 2016 & 1 & 5 & 5 & 1 & 4 & 4 & 4 & 16 & 17 & 2 & \\
\hline 2017 & 3 & 12 & 12 & 10 & 17 & 19 & 15 & 11 & 1 & 9 & \\
\hline 2018 & 5 & 7 & 27 & 5 & 3 & 1 & 5 & 5 & 2 & 27 & \\
\hline \multirow[t]{11}{*}{2019} & 5 & 1 & 1 & 11 & 22 & 15 & 25 & 11 & 15 & 11 & \\
\hline & 38 & 32 & 21 & 21 & 32 & 14 & 35 & 28 & 38 & 35 & $\begin{array}{c}\text { Upper level } \\
{[\mathrm{U}]}\end{array}$ \\
\hline & 1 & 4 & 3 & 1 & 1 & 1 & 1 & 1 & 1 & 2 & $\begin{array}{c}\text { Lower level } \\
\text { [L] }\end{array}$ \\
\hline & 0 & 0 & 0 & 0 & 0 & 0 & 0 & 0 & 0 & 0 & Target [T] \\
\hline & 38 & 32 & 5 & 21 & 32 & 14 & 35 & 28 & 38 & 35 & U-T \\
\hline & 1 & 4 & 3 & 1 & 1 & 1 & 1 & 1 & 1 & 2 & T-L \\
\hline & 38 & 32 & 2 & 21 & 32 & 14 & 35 & 28 & 38 & 35 & $\begin{array}{c}\text { Deviation } \\
\text { about }[\mathrm{T}]\end{array}$ \\
\hline & 5 & 16 & 1 & 5 & 5 & 16 & 16 & 16 & 30 & 14 & $\mathrm{C}$ \\
\hline & 0.57143 & 0.457 & 1.14286 & 0.156 & 0.23809 & 0.5 & 0.5 & 0.131 & 0.78948 & 0.4 & $\mathrm{~K}=\mathrm{C} / \mathrm{D}$ \\
\hline & 9.85714 & 16.14 & 8 & 14.29 & 10.5714 & 17.715 & 13 & 14.71 & 10.7143 & 13.15 & Avg. \\
\hline & 118.144 & 172.8 & 24.6667 & 145.2 & 62.9523 & 135.24 & 87.3334 & 174.2 & 193.571 & 164.2 & Variance \\
\hline 1301 & 123.03 & 198.1 & 101.33 & 54.58 & 41.6 & 224.52 & 128.17 & 51.41 & 243.45 & 134.7 & Loss \\
\hline 1300.97 & \multicolumn{2}{|c|}{321.16} & \multicolumn{2}{|c|}{155.91} & \multicolumn{2}{|c|}{266.12} & \multicolumn{2}{|c|}{179.58} & \multicolumn{2}{|c|}{378.2} & Total Loss \\
\hline
\end{tabular}

Figure 7 illustrates the significance of HBL elements via measure ideality response value discussed in Equation (5) to instruct the Neural Networks at the tracking and controlling stages of the proposed LSPL framework. The figure further demonstrates the high impact of the interaction between environment and enterprise culture toward the Lean Safety approach, as illustrated in Figure 8, which is more than a social policy interference and affects the technology on management modeled on [47].

Figure 9 illustrates the interference of social and policy on ideality value for the Lean Safety approach, while Figure 10 illustrates the interference of the environment with technology.

The results illustrated in Table 16 for the goodness of fit of the test stage for the measurement performance for the LSPL implementation are summarized. The values of SRMR, RMSEA, $x^{2}$, and the p-value were satisfactory, while the values of GFI and AGFI were not. 


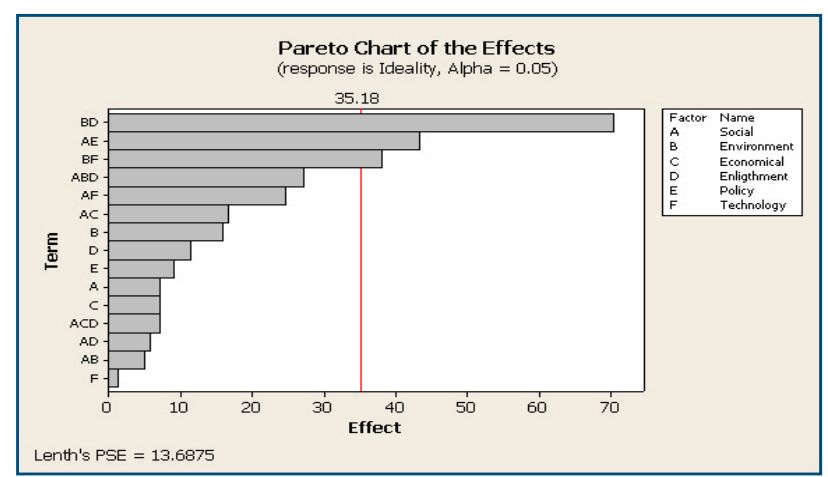

Figure 7. Significance HBL elements on IAPTC (Identify Analysis Perform Track Control) stages and ideality response.

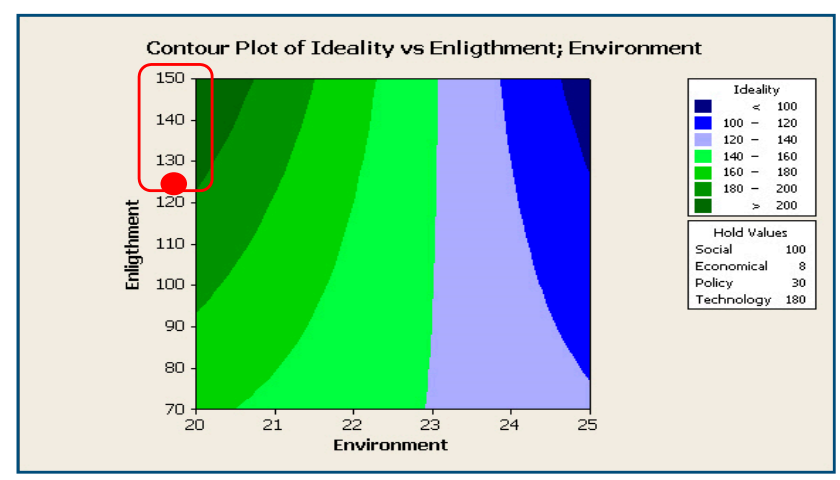

Figure 8. Impact of Environment and enterprises culture interference.

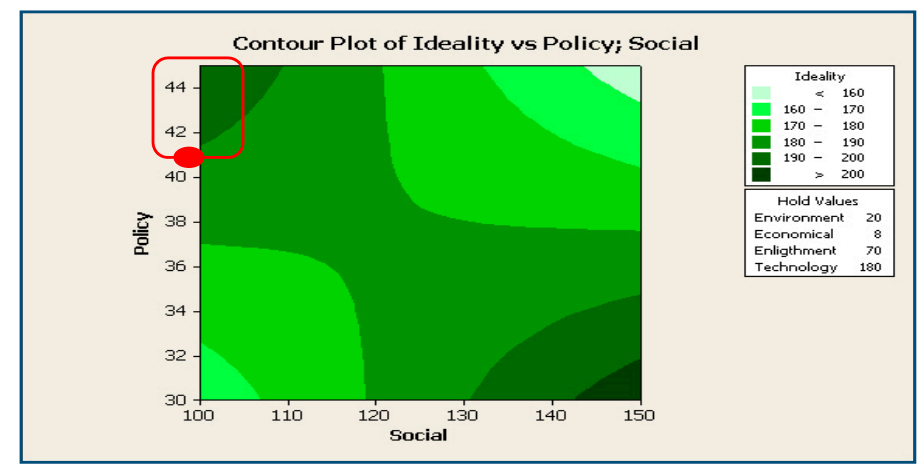

Figure 9. Impact of environment and enterprises technology interference.

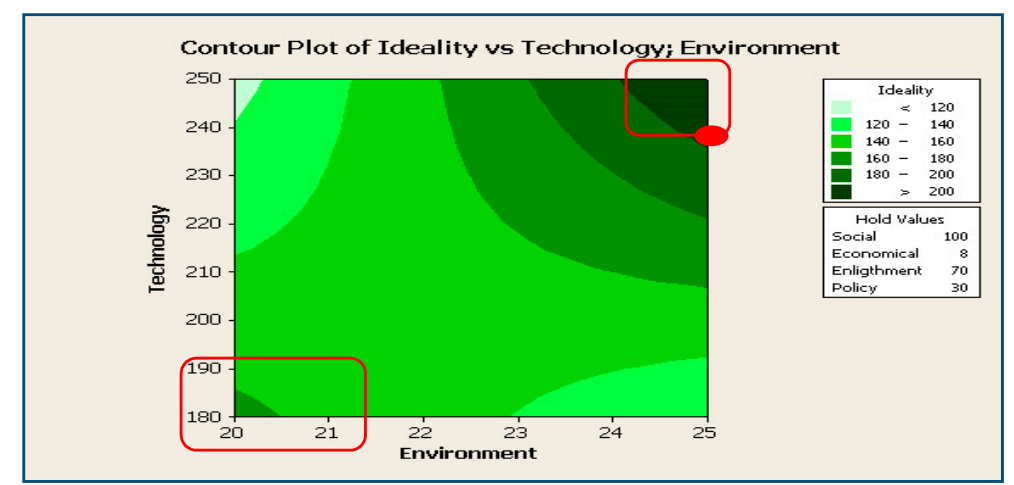

Figure 10. Impact of Environment and enterprises technology interference. 
Table 16. Results of fit indices for CFA.

\begin{tabular}{ccccccccc}
\hline LSPL & $\mathbf{x}^{2}$ & d.f & $\mathbf{x}^{2} /$ d.f & GFI & AGFI & CFI & SRMR & RMSEA \\
\hline $\begin{array}{c}\text { Measurement } \\
\text { values }\end{array}$ & 562.175 & 237 & 2.030 & 0.831 & 0.820 & 0.974 & 0.071 & 0.074 \\
$\begin{array}{c}\text { Recommended } \\
\text { values }\end{array}$ & & & $\leq 0.30$ & $\geq 0.90$ & $\geq 0.90$ & $\geq 0.90$ & $\leq 0.08$ & $\leq 0.08$ \\
\hline
\end{tabular}

GFI: Goodness of Fit Index [0:1], AGFI: Adjusted Goodness of Fit Index [0:1], CFI: Comparative Fit Index. SRMR: Standardized Root Mean Square Residual, RMSEA: Root Mean Square Error of Approximation.

Table 17 illustrates the correlations between influencing variables, while the off-diagonal elements represent the eigenvalue. The mean square roots of variances should be greater than the correlation between a particular influencing variable and other influencing variables. The statistics illustrated in Table 15 satisfied the overall requirement as lending to discriminant validity and evidence to construct validity [46].

Table 17. Correlation matrix and average variance extracted (AVE).

\begin{tabular}{|c|c|c|c|c|c|}
\hline LSPL Stages & $\begin{array}{l}\text { Identify and } \\
\text { Planning } \\
\text { Stage }\end{array}$ & $\begin{array}{l}\text { Design Stage } \\
\text { Instruments }\end{array}$ & $\begin{array}{l}\text { Tracking and } \\
\text { Test Stage }\end{array}$ & $\begin{array}{l}\text { Work Safety } \\
\text { and Control } \\
\text { Performance }\end{array}$ & $\begin{array}{l}\text { Expected Lean } \\
\text { Performance }\end{array}$ \\
\hline $\begin{array}{l}\text { Identify and Planning } \\
\text { stage }\end{array}$ & 0.881 & & & & \\
\hline $\begin{array}{l}\text { Design stage } \\
\text { instruments }\end{array}$ & $0.608^{* *}$ & 0.787 & & & \\
\hline Tracking and Test stage & $0.534 * *$ & $0.693 * *$ & 0.819 & & \\
\hline $\begin{array}{l}\text { Work safety and control } \\
\text { performance }\end{array}$ & $0.397^{* *}$ & $0.657^{* *}$ & $0.638^{* *}$ & 0.949 & \\
\hline $\begin{array}{l}\text { Expected Lean } \\
\text { performance }\end{array}$ & $0.429^{* *}$ & $0.449^{* *}$ & 0.540 ** & $0.640 *$ & 0.851 \\
\hline CR & 0.946 & 0.919 & 0.924 & 00.974 & 0.913 \\
\hline AVE & 0.777 & 0.620 & 0.671 & 0.902 & 0.725 \\
\hline
\end{tabular}

\section{Sustainable Lean Safety Performance Enhancement}

The improvement was done by tracking the activities in time-at-risk cases during the studying interval. This work resorted to using an optimization tool such as Artificial Neural Networks (ANN) because there are no linear dependencies between input and output data (i.e., evaluate all possible values of a certain "unknown" function) by solely establishing the nonlinear relations between input or output datasets, based on the learning process itself. The ANN has the ability to force using the Simple Moving Average (SMA) to monitor the VA and NNVA activities with time. Finally, at the end of the run, will obtain the array of SMA values for each time-cost at a moment $t$.

Table 18 illustrates the Neural Network input data. The number of neurons is 21, while the second layer of network models has 19 neurons. The regression analysis was implemented on a specific training data set loaded on the local dataset to determine highly accuracy running performance with correlation coefficient $R$, which approximates a value of 0.999 . The performance of tracking the faults interval via MSE of 0.027 at Epoch 3 and the R between the target and output for validation data was 0.9744. The results of testing for ANN used in this work illustrated in Figure 11, where the convergence becomes valid when the $\mathrm{R}$ between standard values calculated from Table 13 and predicted output is > $80 \%$, to reduce the defects related with faults similar to the Lindstrom et al. approach to reach zero faults [47]. 
Table 18. Limits of input variables in the Neural Network model.

\begin{tabular}{cccc}
\hline & Parameters & Down & Up \\
\hline$X_{1}$ & Neuron number & 2 & 25 \\
$X_{2}$ & Learning rate & 0.01 & 0.4 \\
$X_{3}$ & Training epoch & 100 & 2500 \\
$X_{4}$ & Momentum constant & 0.1 & 0.9 \\
$X_{5}$ & Number of training runs & 3 & 7 \\
\hline
\end{tabular}
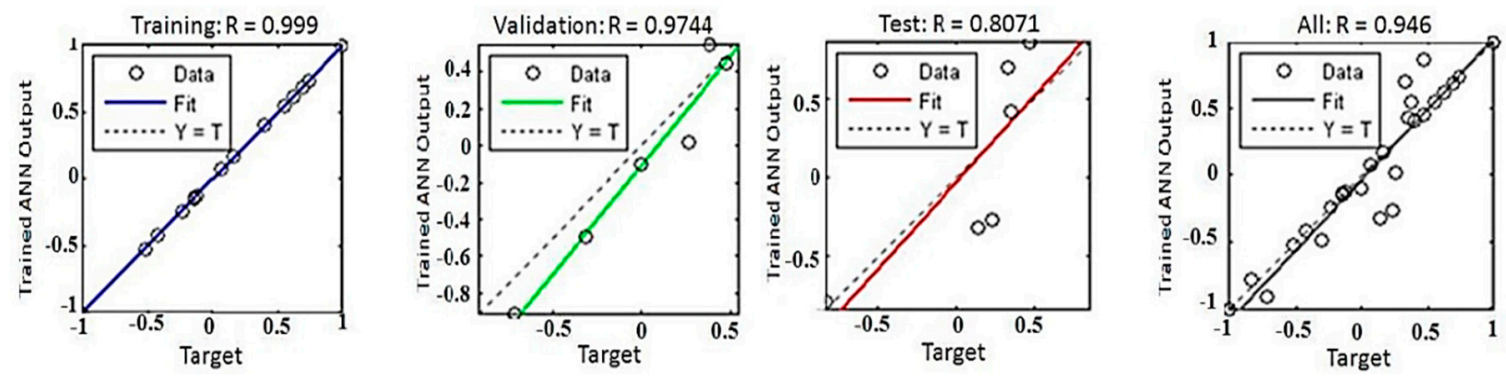

Figure 11. Training result of the proposed network.

Figure 12 illustrates the standard value deduced from Table 13 vs. the output plot for the trained ANN simulated by all training dataset stored on the ERP's enterprise system via running the code in Appendix A. The performance of the network can be improved if training data increasingly take into account the effect of Fault Tree Analysis (FTA), as discussed by Shafiee [48], where authors suffered from collecting the data, where it is collected in the manufacturing environment, not a laboratory environment.

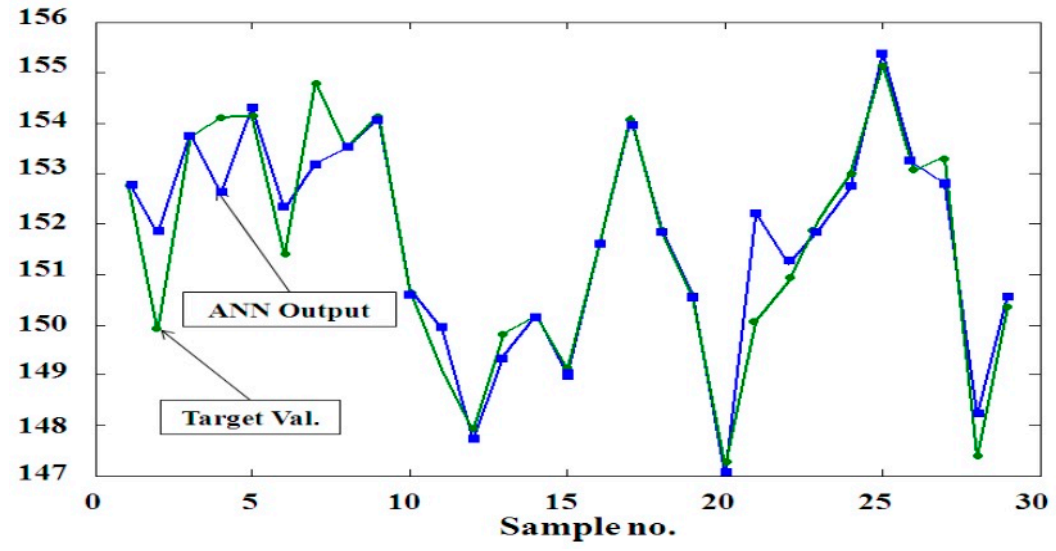

Figure 12. Trained Artificial Neural Network (ANN) standard output vs. target plot to (TaTS1).

The entire process of SMA computation for the functions that have high influence values and appear in Table 13 (i.e., the TaTS1 variable) are illustrated in Figure 11 and tracked closely. When considered other influencing variables, the performance is enhanced as illustrated in Figure 12. Before creating and training an ANN to predict future values of process deviation according to time that modeled on SMA steps. Some portion of the dataset generated and trained the proposed Neural Network on the dataset being generated. The statement's code snippets that perform training samples generation are listed below. This code was modeled on the steps of Abed et al. at IEOM 2018 [43].

\section{Conclusions}

The paper aims at establishing a unified safety procedures framework works through the proposed roadmap that derivative of DMAIC and enhance its Measurement and Analysis phases and called 
the Sub-Road-Map (LSPL), which activating through a proposed framework named the LSPL that follows the Lean for its excellence in cost controlling due to fault tracking. The proposed framework needs extra efforts from the workers and their enterprise's enlightenment, to audit the relationship of costs (e.g., maintainability costs plus consuming downtime) as articulated in Table 12 and their costs, articulated in Table 1. The triggering of the proposed algorithm by forecasting the precise faults of the performance level of the Lean Safety approach via an ideality value extracting from FMEF steps to determine their severity, occurrence, and detecting it as discussed in Table 10 to feed the Neural Network code to predict the behavior of the enterprises toward their faults control before exacerbate in a timely fashion via followed process deviation as illustrated in Figures 11 and 12.

Oddly enough, it was found in the analysis of the questionnaire's data collected from 2014 to 2019, the enterprises' behaviors tend to be more task-oriented (Theory N) [46], as illustrated in Figures 4 and 5, emanating from Figure 1. The LSPL and its LSPL framework reduce the enterprise's costs related to downtimes to $0.037 \%$. Consequently, the fault per million opportunities that corresponding FPMO table is 5.78/6, which declares the Lean Safety Performance Level to $96.333 \%$, which according to Table 11 illustrates that the enterprise becomes near safe and under ongoing control.

Author Contributions: Conceptualization, A.M.A. and S.E.; methodology, A.M.A. and S.E.; validation, A.M.A.; formal analysis, A.M.A.; investigation, S.E.; resources, A.M.A.; data curation, A.M.A., S.E.; writing-original draft preparation, A.M.A., S.E., and F.A.; writing-review and editing, S.E.; supervision, A.M.A.; project administration, A.M.A. and S.E.; software F.A. All authors have read and agreed to the published version of the manuscript.

Funding: This research project was funded by the Deanship of Scientific Research, Princess Nourah bint Abdulrahman University, through the Program of Research Project Funding after Publication, grant No (41-PRFA-P-36).

Conflicts of Interest: The authors declare no conflict of interest.

\section{Appendix A}

The Neural Network training code

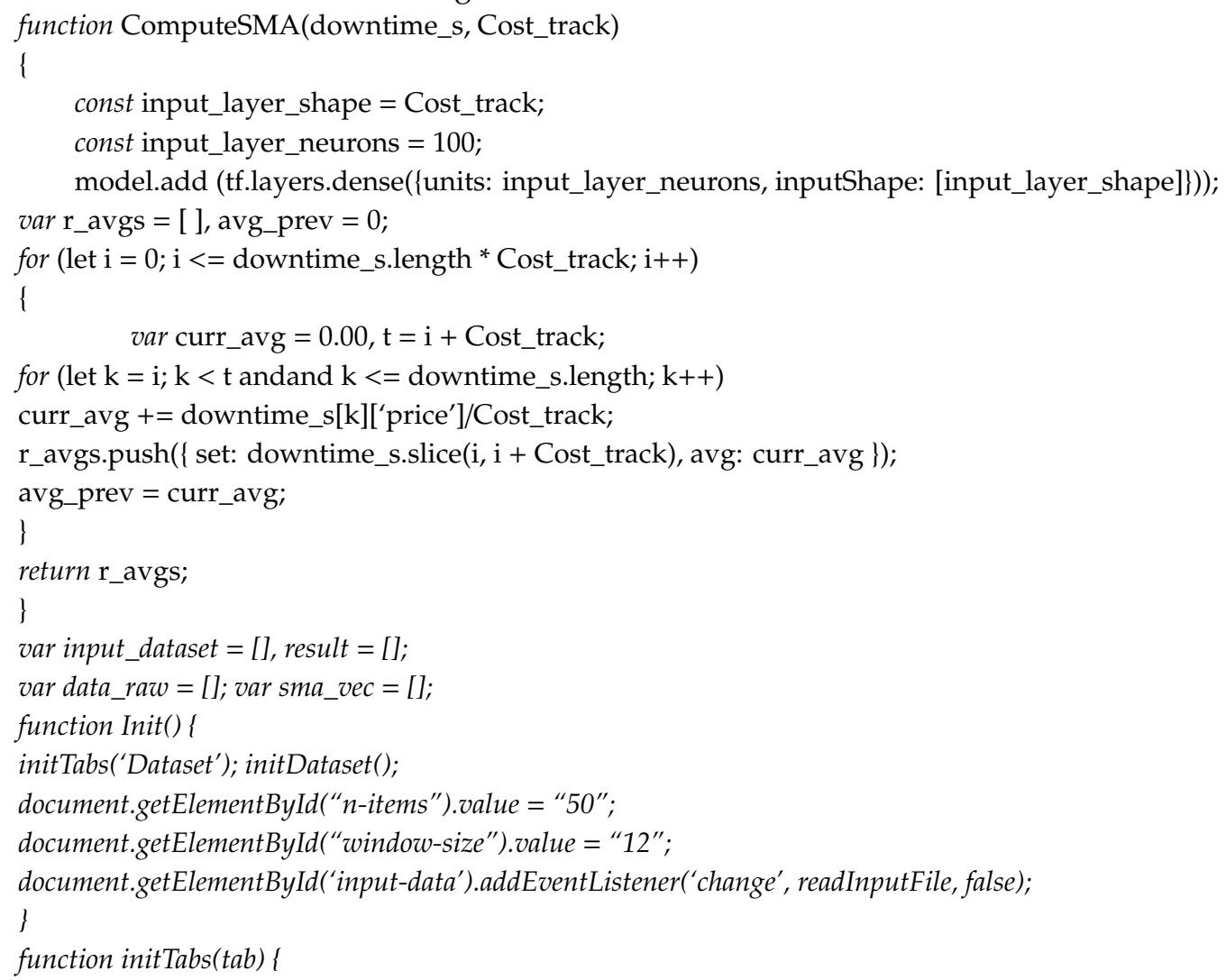




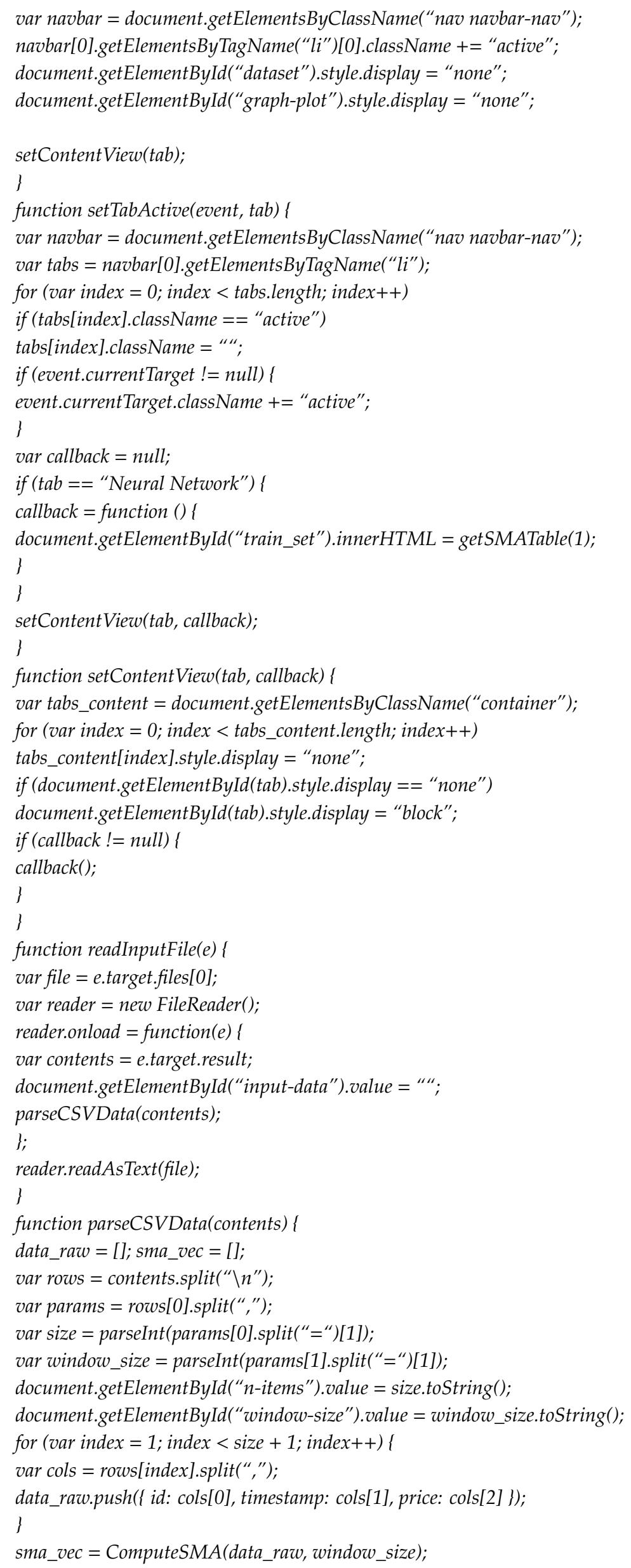


onInputDataClick();

\}

function initDataset() \{

var n_items = parseInt(document.getElementById("n-items").value);

var window_size = parseInt (document.getElementById("window-size").value);

data_raw = GenerateDataset $\left(n \_\right.$items $)$;

sma_vec $=$ ComputeSMA $($ data_raw, window_size $)$;

onInputDataClick();

\}

async function onTrainClick() \{

var inputs $=$ sma_vec.map $($ function $(\operatorname{inp} f)\{$

return inp_f['set'].map(function(val) \{ return val['price']; \})\});

var outputs = sma_vec.map $($ function $($ outp_f) $\{$ return outp_f['avg']; $\})$;

var n_epochs = parseInt (document.getElementById("n-epochs").value);

var window_size = parseInt (document.getElementById("window-size").value);

var lr_rate = parseFloat (document.getElementById("learning-rate").value);

var $n \_h l=$ parseInt (document.getElementById("hidden-layers").value);

var $n$ _items = parseInt(document.getElementById("n-items-percent").value);

var callback $=$ function $($ epoch, $\log )\{$

var log_nn = document.getElementById("nn_log").innerHTML;

log_nn $+=$ "<div>Epoch: " + (epoch +1$)+$ "Loss: " + log.loss + "</div >";

document.getElementById("nn_log").innerHTML = log_nn;

document.getElementById ("training_pg").style.width $=\left((\right.$ epoch +1$) *\left(100 / n \_\right.$epochs $\left.)\right)$.toString ()$+$"\%";

document.getElementById("training_pg").innerHTML $=\left((\right.$ epoch +1$) *\left(100 / n \_\right.$epochs $\left.)\right)$.toString ()$+$"\%";

\}

result = await trainModel(inputs, outputs,

n_items, window_size, $n \_$epochs, $l r \_r a t e, n \_h l$, callback);

alert('Your model has been successfully trained...');

\}

function onPredictClick(view) \{

var inputs = sma_vec.map (function $(\operatorname{inp} f)\{$

return inp_f['set'].map(function (val) \{ return val['price'] ; \}); \});

var outputs = sma_vec.map $($ function $($ outp $f)\{$ return outp_fl'avg' $] ;\})$;

var $n \_$items = parseInt(document.getElementById("n-items-percent").value);

var outps = outputs.slice(Math.floor(n_items/100* outputs.length), outputs.length);

var pred_vals $=$ Predict(inputs, $n \_$items, result['model']);

vardata_output $=$ "“";

for (var index $=0$; index $<$ pred_vals.length; index ++ ) \{

data_output $+=$ " $\langle$ tr $>\langle t d\rangle "+($ index +1$)+"</ t d\rangle\langle t d\rangle "+$

outps[index $]+"</ t d\rangle\langle t d\rangle "+$ pred_vals[index $]+"</ t d\rangle\langle/ t r\rangle " ;$

\}

document.getElementById("pred-res").innerHTML $=$ " $<$ table class $=\backslash$ "table $\backslash$ " $><$ thead $><$ tr $><$ th

scope $=\backslash "$ col $\backslash ">\#</$ th $><$ th scope $=\backslash "$ col $\backslash ">$ Real Value $<\mid$ th $>\backslash$

$<$ th scope $=\backslash$ "col $\backslash ">$ Predicted Value $</$ th $></$ thead $><$ tbody $>$ " data_output + " $<$ tbody $></$ table $>$ ";

var window_size = parseInt(document.getElementById("window-size").value);

var timestamps_ $a=$ data_raw.map(function (val) \{ return val['timestamp']];\});

var timestamps_b $=$ data_raw.map (function (val) \{

return val['timestamp']]; \}).splice(window_size, data_raw.length);

var timestamps_c $=$ data_raw.map(function (val) \{

return val['timestamp']; \}).splice(window_size + Math.floor(n_items/100 * outputs.length), data_raw.length);

var sma = sma_vec.map $($ function (val) $\{$ return val['avg'] $]\})$;

var prices $=$ data_raw.map $($ function $(v a l)\{$ return val['price'] $\})$;

var graph_plot $=$ document.getElementById('graph-pred'); 
Plotly.newPlot (graph_plot, [\{ $x$ : timestamps_a, y: prices, name: “Series" $\}],\{$ margin: $\{t: 0\}\})$ );

Plotly.plot (graph_plot, [\{ $x$ : timestamps_b, y: sma, name: "SMA" $\}],\{$ margin: $\{t: 0\}\})$;

Plotly.plot (graph_plot, [\{x: timestamps_c, y: pred_vals, name: "Predicted" \}], \{ margin: $\{t: 0\}\})$;

\}

function getInputDataTable() \{

var data_output $=$ "“";

for (var index $=0$; index $<$ data_raw.length; index ++ )

\{

data_output $+=$ " $<t r\rangle\langle t d\rangle "+$ data_raw[index]['id'] + " $\langle/ t d\rangle\langle t d\rangle "+$

data_raw[index]['timestamp'] + " $</ t d><t d>"+$ data_raw[index]['price'] + " $</ t d></ t r>$;

\}

return " $<$ table class $=\backslash$ "table $\backslash$ " $><$ thead $><$ tr $><$ th scope $=\backslash$ "col $\backslash ">\#</$ th $><$ th scope $=\backslash$ "col $\backslash$ " $>$ Timestamp $</$ th $>\backslash$ $<$ th scope $=\backslash "$ col $\backslash ">$ Feature $</$ th $></$ thead $><$ tbody $>$ " + data_output $+"</$ tbody $></$ table $>$ ";

\}

function getSMATable(view) \{

vardata_output $=$ "“";

if (view $==0)$ \{

for (var index $=0$; index $<$ sma_vec.length; index ++ )

i

var set_output $=$ "“";

var set $=$ sma_vec[index $][$ 'set' $]$;

for (var $t=0 ; t<$ set.length; $t++)\{$

set_output $+=$ " $<$ tr $><t$ d width $=\backslash " 30 p x \backslash ">$ " + set[t]['price'] +

$"</ t d><t d>"+\operatorname{set}[t][$ 'timestamp'] + " $</ t d></$ tr $>$ ";

\}

data_output $+=$ " $<$ tr $><t$ t width $=\backslash " 20 p x \mid ">$ " $+($ index +1$)+$

" $<\mid t d><t d>"+$ " $<$ table width $=\backslash " 100 p x \mid "$ class $=\backslash$ "table $\backslash ">$ " set_output +

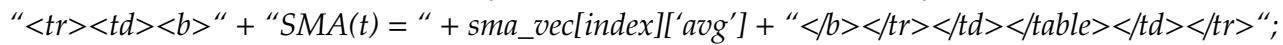

\}

return " $<$ table class $=\backslash$ "table $\backslash "><$ thead $><$ tr $><$ th scope $=\backslash$ "col $\backslash$ " $>\#</$ th $><$ th scope $=\backslash$ "col $\backslash$ " $>$ Time Series $</$ th $>\mid$

$<$ thead $><$ tbody $>$ " + data_output + " $<$ tbody $><$ table $>$ ";

\}

else if (view $==1)\{$

var set $=$ sma_vec.map $($ function (val) $\{$ return val['set']; \});

for (var index $=0$; index $<$ sma_vec.length; index ++ )

i

data_output $+=$ " $<$ tr $><t$ d width $=\backslash " 20 p x \backslash ">$ " $+($ index +1$)+$

$"<|t d\rangle\langle t d>["+\operatorname{set}[$ index].map(function (val) \{

return (Math.round(val['price'] * 10000)/10000).toString(); \}).toString()+

"] $</ t d><t d>$ " sma_vec[index]['avg'] + " $</ t d></ t r>$;

\}

return " $<$ table class $=\backslash$ "table $\backslash "><$ thead $><$ tr $><$ th scope $=\mid$ "col $\backslash ">\#</$ th $><$ th scope $=\backslash$ "col $\backslash ">\mid$

Input $</$ th $><$ th scope $=\mid$ "col $\backslash$ " $>$ Output $</$ th $></$ thead $><$ tbody $>$ " data_output + "</tbody $></$ table $>$ ";

\}

\}

function onInputDataClick() \{

document.getElementById("dataset").style.display = "block";

document.getElementById("graph-plot").style.display = "block";

document.getElementById("data").innerHTML = getInputDataTable();

var timestamps = data_raw.map (function (val) \{ return val['timestamp']; \});

var prices $=$ data_raw.map $($ function (val) $\{$ return val['price'] $]\})$;

var graph_plot = document.getElementById('graph'); 
Plotly.newPlot (graph_plot, [\{ $x$ : timestamps, y: prices, name: “Stocks Prices" \}], \{ margin: $\{t: 0\}\}$ );

\}

function onSMAClick() \{

document.getElementById("data").innerHTML = getSMATable(0);

var sma $=$ sma_vec.map $($ function (val) $\{$ return val['avg'] $]\})$;

var prices $=$ data_raw.map $($ function (val) $\{$ return val['price'] $]\})$;

var window_size = parseInt(document.getElementById("window-size").value);

var timestamps_ $a=$ data_raw.map(function (val) \{ return val['timestamp']];\});

var timestamps_b=data_raw.map(function (val) \{

return val['timestamp']; \}).splice(window_size, data_raw.length);

var graph_plot $=$ document.getElementById('graph');

Plotly.newPlot (graph_plot, [\{ $x$ : timestamps_a, y: prices, name: “Series" \}], \{ margin: $\{t: 0\}\})$;

Plotly.plot(graph_plot, [\{x: timestamps_b,y: sma, name: "SMA" \}], \{margin: $\{t: 0\}\})$;

\}

function ComputeSMA(time_s, window_size)

\{

var r_avgs $=[]$, avg_prev $=0$

for $($ let $i=0 ; i<=$ time_s.length - window_size; $i++)$

i

var curr_avg $=0.00, t=i+$ window_size;

for $($ let $k=i ; k<$ t andand $k<=$ time_s.length $;++)$

curr_avg $+=$ time_s[ $k][$ 'price' $] /$ window_size;

r_avgs.push(\{ set: time_s.slice $(i, i+$ window_size), avg: curr_avg \});

avg_prev =curr_avg;

\}

return r_avgs;

\}

function GenerateDataset(size)

\{

var dataset $=[]$;

var $d t 1=$ new Date(), dt2 = new Date();

dt1.setDate (dt1.getDate() - 1);

dt2.setDate(dt2.getDate() - size);

var time_start $=d t 2$.getTime () ;

var time_diff $=$ new Date().getTime () - dt1.getTime();

let curr_time $=$ time_start;

for (let $i=0 ; i<$ size; $i++$, curr_time+=time_diff) \{

var curr_dt = new Date(curr_time);

var hours = Math.floor (Math.random( $) * 100 \% 24)$;

var minutes $=$ Math.floor $($ Math.random ()$* 100 \% 60)$;

var seconds = Math.floor (Math.random ()$* 100 \% 60)$;

dataset.push( $($ id: $i+1$, price: (Math.floor (Math.random ()$* 10)+5)+$ Math.random () ,

timestamp: curr_dt.getFullYear ()$+"$-" + ((curr_dt.getMonth ()$>9)$ ? curr_dt.getMonth( $):(" 0 "+$ curr_dt.getMonth())) + "-" +

$(($ curr_dt.getDate ()$>9) ?$ curr_dt.getDate ()$:(“ 0 "+$ curr_dt.getDate ()$))+$ " [" + ((hours > 9) ? hours : (“0" + hours $))$ $+$

$": "+(($ minutes $>9) ?$ minutes $:(" 0 "+$ minutes $))+": "+(($ seconds $>9) ?$ seconds $:(" 0 "+$ seconds $))+$ "]" $\})$;

\}

return dataset;

\}

async function trainModel(inputs, outputs, size, window_size, n_epochs, learning_rate, n_layers, callback) 
1

const input_layer_shape $=$ window_size;

const input_layer_neurons $=100$;

const rnn_input_layer_features $=10$;

const rnn_input_layer_timesteps $=$ input_layer_neurons/rnn_input_layer_features;

const rnn_input_shape $=[$ rnn_input_layer_features, rnn_input_layer_timesteps $]$;

const rnn_output_neurons $=20$;

const rnn_batch_size $=$ window_size;

const output_layer_shape $=$ rnn_output_neurons;

const output_layer_neurons $=1$;

const model $=t f$.sequential () ;

inputs $=$ inputs.slice $(0$, Math.floor(size/100 * inputs.length $))$;

outputs $=$ outputs.slice $(0$, Math.floor(size/100 * outputs.length));

const $x s=t f . t e n s o r 2 d$ (inputs, [inputs.length, inputs[0].length]).div(tf.scalar(10));

const ys $=t f . t e n s o r 2 d($ outputs, [outputs.length, 1]).reshape([outputs.length, 1]).div(tf.scalar(10));

model.add(tf.layers.dense(\{units: input_layer_neurons, inputShape: [input_layer_shape]\}));

model.add(tf.layers.reshape(\{targetShape: rnn_input_shape\}));

var lstm_cells $=[]$;

for (let index $=0$; index $<$ n_layers; index++) \{

lstm_cells.push(tf.layers.lstmCell(\{units: rnn_output_neurons\}));

\}

model.add(tf.layers.rnn(icell: lstm_cells,

inputShape: rnn_input_shape, returnSequences: false\}));

model.add(tf.layers.dense(\{units: output_layer_neurons, inputShape: [output_layer_shape]\}));

const opt_adam $=$ tf.train.adam (learning_rate);

model.compile(\{ optimizer: opt_adam, loss: 'meanSquaredError'\});

const hist $=$ await model.fit $(x s, y s$,

\{ batchSize: rnn_batch_size, epochs: $n \_$epochs, callbacks: \{

onEpochEnd: async (epoch, $\log )=>\{$ callback $($ epoch, $\log ) ;\}\}\}) ;$

return \{ model: model, stats: hist \};

\}

function Predict(inputs, size, model)

i

var inps $=$ inputs.slice $($ Math.floor $($ size/100 * inputs.length $)$, inputs.length $)$;

const outps = model.predict(tf.tensor2d(inps, [inps.length, inps[0].length]).div(tf.scalar(10))).mul(10);

return Array.from(outps.dataSync());

\}

\section{References}

1. Pudar, S.; Manimaran, G.; Liu, C.C. PENET: A practical method and tool for integrated modeling of security attacks and countermeasures. Comput. Secur. 2009, 28, 754-771. [CrossRef]

2. Papadopoulos, Y. Model-based system monitoring and diagnosis of failures using state charts and fault trees. Int. J. Lean Sustain. Engng. Syst. Saf. 2003, 81, 325-341.

3. Zuzek, A.; Biasizzo, A.; Novak, F. Towards a general test presentation in the test sequencing problem. In Proceedings of the Second International On-Line Testing Workshop; IEEE Computer Society Press: Biarritz, France, 1996; pp. 236-237.

4. Biasizzo, A.; Zuzek, A.; Novak, F. Sequential Diagnosis Tool; Microprocessors Microsystems: Ljubljana, Slovenia, 2000; Volume 24, pp. 191-197.

5. Chang, J.I.; Liang, C. Performance Evaluation of Process Safety Management Systems of Paint Manufacturing Facilities. J. Loss Prev. Process Ind. 2009, 22, 398-404. [CrossRef]

6. DuPont Quick 4-Step Review of Process Safety Management. 2016. Available online: http://www2.dupont. com/DuPont_Sustainable_Solutions/en_US/assets/downloads/Quick4-StepReview_Sheet.pdf (accessed on 3 April 2016). 
7. Energy Institute. High Level Framework for Process Safety Management 2016. Available online: https://publishing.energyinst.org/_users/ei2/registered/chizzyelfizzy@yahoo.com/High-level-frameworkfor-process-safety-management070416044249.pdf (accessed on 3 April 2016).

8. Pattipati, K.R.; Alexandridis, M.G. Application of heuristic search and information theory to sequential fault diagnosis. IEEE Trans. Syst. Man Cybern. 1990, 20, 872-887. [CrossRef]

9. Shakeri, M.; Raghavan, V.; Pattipati, K.R.; Patterson-Hine, A. Sequential testing algorithms for multiple fault diagnosis. IEEE Trans. Syst. Man Cybern. Part A Syst. Hum. 2000, 30, 1-14. [CrossRef]

10. Rao, N.S.V. Expected-value analysis of two single fault diagnosis algorithms. IEEE Trans. Comput. 1993, 42, 272-280. [CrossRef]

11. Price, C. Computer-Based Diagnostic Systems; Springer: London, UK, 1999.

12. Paasch, R.; Mocko, G. Incorporating uncertainty in diagnostic analysis of mechanical systems. Trans. ASME J. Mech. Des. 2005, 217, 315-325.

13. Yue, Y.; Li, X.; Zong, Q. Development of Automobile Fault Diagnosis Expert System Based on Fault Tree-Neural Network Ensamble. In Proceedings of the 2011 International Conference on Electronics, Communications and Control (ICECC), Ningbo, China, 9-11 September 2008; pp. 2028-2031.

14. Anvari, A.; Zulkifli, N.; Yusuff, R.M. Evaluation of approaches to safety in lean manufacturing and safety management systems and clarification of the relationship between them. World Appl. Sci. J. 2011, 15, 19-26.

15. Underwood, P.; Waterson, P. Systemic accident analysis: Examining the gap between research and practice. Accid. Anal. Prev. 2013, 55, 154-164. [CrossRef]

16. Andrews, J.D. The use of NOT logic in fault tree analysis. Qual. Lean Sustain. Eng Int. 2001, 17, 143-150. [CrossRef]

17. Billinton, R.; Allan, R.N. Lean Sustainability Evaluation of Engineering Systems, 2nd ed.; Plenum: New York, NY, USA, 1992.

18. Laura, H.I.; Isabelina, N.; James, J. Use of Safety and Lean Integrated Kaizen to Improve Performance in Modular Homebuilding. J. Constr. Eng. Manag. 2011. [CrossRef]

19. Hartini, S.; Ciptomulyono, U. The relationship between lean and sustainable manufacturing on performance: Literature review. Ind. Eng. Serv. Sci. Procedia Manuf. 2015, 4, 38-45. [CrossRef]

20. Kurdve, M.; Zackrisson, M.; Wiktorsson, M.; Harlin, U. Lean and green integration into production system models e experiences from Swedish industry'. J. Clean. Prod. 2014, 85, 180-190. [CrossRef]

21. Potes Ruiz, P.; Kamsu Foguem, B.; Grabot, B. Generating knowledge in maintenance from Experience Feedback. Knowl. Based Syst. 2014, 68, 4-20. [CrossRef]

22. Yu, H.; Chen, Y.; Hassan, S.; Li, D. Dissolved oxygen content prediction in crab culture using a hybrid intelligent method. Sci. Rep. 2016, 6, 72-92. [CrossRef]

23. Sakouhi, A.; Nadeau, S. Integration of Occupational Health and Safety into Lean Manufacturing: Quebec Aeronautics Case Study. Am. J. Ind. Bus. Manag. 2016, 6, 1019-1031. [CrossRef]

24. Kumar, N.; Mathiyazhagan, K. Sustainability in lean manufacturing: A systematic literature review. Int. J. Bus. Excell. 2018. [CrossRef]

25. Brown, A.; Amundson, J.; Badurdeen, F. Sustainable value stream mapping (Sus-VSM) in different manufacturing system configurations: Application case studies. J. Clean. Prod. 2014, 85, 164-179. [CrossRef]

26. Ibrahim, S.; Halim, M.A.; Abed, A.M. Modeling VSM with quality Control using Image Verification. In Proceedings of the AL-Azhar Engineering 11th International Conference, AEIC 11, Cairo, Egypt, 23-24 December 2010; Volume 5, pp. 181-193.

27. Shimada, Y.; Kitajima, T.; Takeda, K. Practical Framework for Process Safety Management Based on Plant Life Cycle Engineering. In Proceedings of the 3rd International Conference on Integrity, Lean Sustainability and Failure, Porto, Portugal, 10 July 2009; pp. 20-24.

28. Nawaz, W.; Linke, P.; Koç, M. Safety and sustainability nexus: A review and appraisal. J. Clean. Prod. 2019, 216, 74-87. [CrossRef]

29. Hyytiä, E.; Righter, R.; Virtamo, J.; Viitasaari, L. On value functions for FCFS queues with batch arrivals and general cost structures. Perform. Eval. J. 2020, 138, 102083. [CrossRef]

30. Fraser, K. Facilities management: The strategic selection of a maintenance system. J. Facil. Manag. 2014, 12, 18-37. [CrossRef]

31. Faccio, M.; Persona, A.; Sgarbossa, F.; Zanin, G. Industrial maintenance policy development: A quantitative framework. Int. J. Prod. Econ. 2014, 147, 85-93. [CrossRef] 
32. Ching, J.M.; Williams, B.L.; Idemoto, L.M.; Blackmore, C.C. How the Lean Method of Jidoka Optimizes Technology Implementation. J. Qual. Patient Saf. 2014, 40, 342-350.

33. Jiménez, M.; Romero, L.; Fernández, J.; Espinosa, M.M.; Domínguez, M. Extension of the Lean 5S Methodology to 6S with An Additional Layer to Ensure Occupational Safety and Health Levels. Sustainability 2019, 11, 3827. [CrossRef]

34. Narkhede, B.E.; Gardas, B.B. Hindrances to sustainable workforce in the upstream oil and gas industries -interpretive structural modelling approach. Int. J. Bus. Excell. 2018, 16, 61-81. [CrossRef]

35. Nehete, R.; Narkhede, B.E.; Raut, R.D. Manufacturing performance and relevance of operational performance to small and medium scale enterprises-literature review. Int. J. Bus. Excell. 2016, 10, 354-391. [CrossRef]

36. Paranitharan, K.P.; Ramesh Babu, T.; Iskanius, P.; Pal Pandi, A. An integrated model for achieving sustainability in the manufacturing industry-An empirical study. Int. J. Bus. Excell. 2018, 16, 82-109. [CrossRef]

37. Khalil, Y.F. A novel probabilistically timed dynamic model for physical security attack scenarios on critical infrastructures. Process Saf. Environ. Prot. 2016, 102, 473-484. [CrossRef]

38. Ramesh, N.; Ravi, A. Determinants of total employee involvement: A case study of cutting tool company. Int. J. Bus. Excell. 2017, 11, 221-240. [CrossRef]

39. Sumant, M.; Negi, A. Review of lean-green manufacturing practices in SMEs for sustainable framework. Int. J. Bus. Innov. Res. 2018, 17, 38-64. [CrossRef]

40. Prescott, L.S.; Taylor, J.S.; Lopez-Olivo, M.A.; Munsell, M.F.; VonVille, H.M.; Lairson, D.R.; Bodurka, D.C. How Low should we Go: A Systematic Review and Meta-Analysis of the Impact of Restrictive Red Blood Cell Transfusion Strategies in Oncology. Cancer Treat. Rev. 2016, 46, 1-8. [CrossRef] [PubMed]

41. NSC 'Elements of an Effective Safety Management System'. 2016. Available online: http://www.nsc.org/ Measure/Pages/elements-of-an-effective-safety-management-system.aspx (accessed on 3 April 2016).

42. Kumar, S.; Kumar, N.; Haleem, A. Conceptualisation of sustainable green Lean Six Sigma: An empirical analysis. Int. J. Bus. Excell. 2015, 8, 210-250. [CrossRef]

43. Abed, A.M.; Ibrahim, M.S. Defect Control via Forecasting of Processes' Deviation as JIDOKA Methodology. In Proceedings of the International Conference on Industrial Engineering and Operations Management, Bandung, Indonesia, 6-8 March 2018, 8th ed.; IEOM Society International: Southfield, MI, USA, 2018; pp. 2436-2449. ISSN 2169-8767. ISBN 978-1-5323-5944-6.

44. Kaepernick, H.; Kara, S. Environmentally Sustainable Manufacturing: A Survey on Industry Practice; Katholieke Universiteit Leuven: Leuven, Belgium, 2006; Available online: http://www.mech.kuleuven.be/lce2006/key5. pdf (accessed on 2 August 2018).

45. Pattipati, K.R. Computationally efficient algorithms for multiple fault diagnosis in large graph-based systems. IEEE Trans. Syst. Man Cybern. Part A Syst. Hum. 2003, 33, 73-85.

46. Occupational Safety and Health Administration (OSHA). Sustainability in the Workplace: A New Approach for Advancing Worker Safety and Health 2016. Available online: www.osha.gov/sustainability (accessed on 30 June 2018).

47. Lindstrom, J.; Kyosti, P.; Birk, W.; Lejon, E. An Initial Model for Zero Defect Manufacturing. Appl. Sci. 2020, 10, 4570. [CrossRef]

48. Shafiee, M.; Enjema, E.; Kolios, A. An Integrated FTA-FMEA Model for Risk Analysis of Engineering Systems: A Case Study of Subsea Blowout Preventers. Appl. Sci. 2019, 9, 1192. [CrossRef]

(C) 2020 by the authors. Licensee MDPI, Basel, Switzerland. This article is an open access article distributed under the terms and conditions of the Creative Commons Attribution (CC BY) license (http://creativecommons.org/licenses/by/4.0/). 